\title{
Methionine adenosyltransferase a2 sumoylation positively regulate Bcl-2 expression in human colon and liver cancer cells
}

\author{
Maria Lauda Tomasi ${ }^{1,2}$, Minjung Ryoo ${ }^{1,2}$, Komal Ramani, ${ }^{1,2}$, Ivan Tomasi ${ }^{3}$, Pasquale \\ Giordano ${ }^{4}$ José M. Mato ${ }^{5}$, Shelly C. Lu' ${ }^{1,2}$ \\ ${ }^{1}$ Division of Gastroenterology, Cedars-Sinai Medical Center, Los Angeles, CA 90048, USA \\ ${ }^{2}$ USC Research Center for Liver Diseases, Keck School of Medicine of University of Southern California, Los Angeles, CA 90033, USA \\ ${ }^{3}$ General Surgery Department, Rotherham Hospital, Rotherham S60 2UD, UK \\ ${ }^{4}$ Colorectal Department, Barts Health, London E11 1NR, UK \\ ${ }^{5}$ CIC bioGunE, Centro de Investigación Biomédica en Red de Enfermedades Hepáticas y Digestivas (Ciberehd), Technology, \\ Park of Bizkaia, 48160 Derio, Bizkaia, Spain
}

Correspondence to:

Shelly C. Lu, e-mail: shelly.lu@cshs.org

Keywords: methionine adenosyltransferase a2, Bcl-2, ubiquitin-conjugating enzyme 9, sumoylation, colon cancer

Received: June 09, 2015

Accepted: September 15, 2015

Published: September 25, 2015

\section{ABSTRACT}

Ubiquitin-conjugating enzyme 9 (Ubc9) is required for sumoylation and inhibits apoptosis via $\mathrm{Bcl}-2$ by unknown mechanism. Methionine adenosyltransferase $2 \mathrm{~A}$ (MAT2A) encodes for MAT $a 2$, the catalytic subunit of the MATII isoenzyme that synthesizes S-adenosylmethionine (SAMe). Ubc9, Bcl-2 and MAT2A expression are up-regulated in several malignancies. Exogenous SAMe decreases Ubc9 and MAT2A expression and is pro-apoptotic in liver and colon cancer cells. Here we investigated whether there is interplay between Ubc9, MAT2A and Bcl-2. We used human colon and liver cancer cell lines RKO and HepG2, respectively, and confirmed key finding in colon cancer specimens. We found MATa 2 can regulate $\mathrm{Bcl}-2$ expression at multiple levels. MATa2 binds to $B \mathrm{Cl}-2$ promoter to activate its transcription. This effect is independent of SAMe as MATa2 catalytic mutant was also effective. MATa2 also directly interacts with $\mathrm{Bcl}-2$ to enhance its protein stability. MATa2's effect on Bcl-2 requires Ubc9 as MATa2's stability is influenced by sumoylation at K340, K372 and K394. Overexpressing wild type (but not less stable MATa2 sumoylation mutants) protected from 5-fluorouracil-induced apoptosis in both colon and liver cancer cells. Colon cancer have higher levels of sumoylated MATa2, total MATa2, Ubc9 and Bcl2 and higher MATa2 binding to the BCl-2 P2 promoter. Taken together, Ubc9's protective effect on apoptosis may be mediated at least in part by sumoylating and stabilizing MAT $a 2$ protein, which in turn positively maintains $\mathrm{Bcl}-2$ expression. These interactions feed forward to further enhance growth and survival of the cancer cell.

\section{INTRODUCTION}

SUMO is a small ubiquitin-like protein that can be covalently attached to proteins through the formation of isopeptide bonds with specific lysine residues of target proteins [1]. Four SUMO family members (SUMO-1 to -4$)$ are encoded by distinct genes in mammals [2].
SUMO-1 regulates protein stability and activity with crucial implications for many cellular pathways [3]. In contrast, protein conjugates with heterologous SUMO-2/3ubiquitin chains are preferentially targeted for proteasome degradation and the function of SUMO-4 is unknown [4-6]. Sumoylation is a multiple-step process, involving maturation, activation, conjugation and ligation [1]. 
Ubiquitin conjugating enzyme 9 (Ubc9) is the only E2 conjugating enzyme and therefore a key regulator of the sumoylation machinery, transferring the activated SUMO to protein substrates [7]. Sumoylation is involved in many vital processes including transcriptional regulation, signal transduction, protein degradation, cell cycle regulation, chromatin organization, and nuclear transport [8]. Dysregulated sumoylation contributes to carcinogenesis by affecting post-transcriptional modification of key proteins [9], including those involved in cancer metastasis [10-12].

Ubc9 has been shown to be a positive regulator of B-cell lymphoma 2 (Bcl-2) expression in breast cancer cell line MCF-7 [13]. Furthermore, higher rate of apoptosis and poor survival in the MCF-7 cells expressing dominant negative Ubc9 were associated with down-regulation of Bcl-2 [14]. Effect of Ubc9 on Bcl-2 expression was thought to be mediated by the estrogen receptor in MCF-7 cells [13], but the exact mechanism was not explored. Bcl-2 was identified first as an apoptotic regulator, the oncoprotein activated via chromosome translocation in human follicular lymphoma [15]. Bcl-2 acts by promoting cell survival rather than by driving cell proliferation as critical step in tumor development [15].

Methionine adenosyltransferase (MAT) is an essential cellular enzyme that catalyzes the formation of S-adenosylmethionine (SAMe), the principal biological methyl donor [16]. In mammals, this essential enzyme is the product of two different genes, $M A T 1 A$ and $M A T 2 A$, which display a distinct pattern of expression among different tissues. MAT1A encodes for $\alpha 1$ that forms dimer (MATIII) and tetramer (MATI) that are predominantly expressed in liver parenchymal cells; while $M A T 2 A$ encodes the a 2 catalytic subunit of the MATII isoenzyme that is expressed in all other tissues [16]. Human liver and colon cancers have higher MAT2A expression [17-19], which is essential for growth as silencing MAT2A by sequence-specific small interfering RNA (siRNA) inhibited growth and induced apoptosis $[19,20]$. We reported that SAMe treatment lowered Ubc9 protein expression and sumoylation in liver, colon and breast cancer cell lines [10]. We also reported SAMe treatment lowered MAT2A expression and is pro-apoptotic in liver and colon cancer cell lines $[17,20]$. Since SAMe lowers the expression of both Ubc9 and MAT2A and knockdown of Ubc9 and MAT2A leads to apoptosis, we examined whether there might be interplay between MAT2A and Bcl-2 that is regulated by sumoylation. In the course of this work, we uncovered highly novel aspects of MAT 22 function, namely the ability of MAT $\alpha 2$ to regulate $\mathrm{Bcl}-2$ expression by transcriptional and post-translational mechanisms that is modulated by sumoylation.

\section{RESULTS}

\section{Effects of SAMe and methylthioadenosine (MTA) on Bcl-2 expression in HepG2 and RKO cells}

We previously reported that treatment with SAMe and its metabolite MTA induced apoptosis in HepG2 and RKO cells $[19,20]$ and lowered Ubc9 protein stability [10]. Ubc9 has been shown to regulate apoptosis as a positive regulator of $\mathrm{Bcl}-2$ expression in breast cancer $\mathrm{MCF}-7$ cells [14]. We next examined whether Ubc9 also regulate apoptosis and Bcl-2 expression in HepG2 and RKO cells. Treatment of HepG2 and RKO cells with Ubc9 siRNA (siUbc9) for 48 hours, or SAMe $(2 \mathrm{mM})$ or MTA (1 mM) for 24 hours increased \% apoptosis more than 5-, 3- and 3.5-fold, respectively (Figure 1A-1B). In both HepG2 and RKO cells, knockdown of Ubc9 lowered Bcl-2 mRNA level after 48 hours by $39 \%$ and $40 \%$ (Figure 1C-1D), respectively. However, Western blot analysis shows the Bcl-2 protein level decreased by $\sim 70 \%$ in both of cell lines (Figure 1C-1D). SAMe and MTA treatment also reduced Bcl-2 mRNA and protein levels (Figure 1E-1F).

\section{Effect of MAT2A silencing on Bcl-2 expression in HepG2 and RKO cells}

Bcl-2 protein has well-known anti-apoptotic functions $[21,22]$. In addition to lowering Ubc9 and Bcl-2 expression, SAMe and MTA treatment also lowered MAT2A expression [20] and knockdown of MAT2A in HepG2 and RKO cells induced apoptosis [17, 19]. These observations prompted us to examine whether there is interplay between MAT2A, Ubc9 and Bcl2. We used a gene silencing and overexpression of MAT2A approach in combination with siUbc9 or siSUMO- 1 for 48 hours in HepG2 and RKO cells. Knockdown of MAT2A resulted in a $45 \%$ and 50\% reduction in Bcl-2 mRNA level compared to a negative control siRNA, respectively, similar to the effects of siUbc9 and siSUMO-1 treatments (Figure 2A and Supplementary Figure S1A). Interestingly, overexpression of MAT2A increased Bcl-2 mRNA level by 3.3- and 3.4fold as compared empty vector control and this inductive effect was largely eliminated if cells were also treated with siUbc 9 or siSUMO-1 (Figure 2A and Supplementary Figure $\mathrm{S} 1 \mathrm{~A})$. We next examined the $\mathrm{Bcl}-2$ promoter activity under the same experimental conditions in HepG2 and RKO cells. Figure 2B and Supplementary Figure S1B show that $B c l-2$ promoter activity highly correlated with the mRNA level results; specifically, knockdown of MAT2A, Ubc9 or SUMO-1 all lowered $B c l-2$ promoter activity, while overexpression of MAT2A increased $B c l-2$ promoter activity but not if either Ubc9 or SUMO-1 was knocked down (Figure 2B and Supplementary Figure S1B). Figures 2C and Supplementary Figure S1C show Western blot analyses under the same experimental conditions. MAT2A, Ubc9 or 
A.

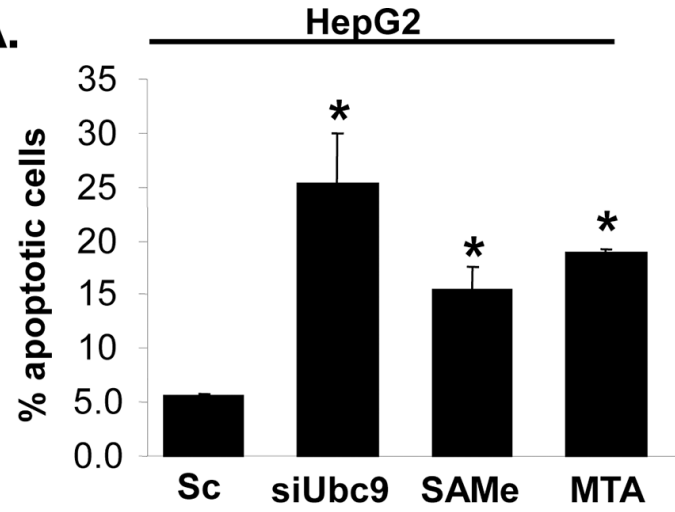

C.

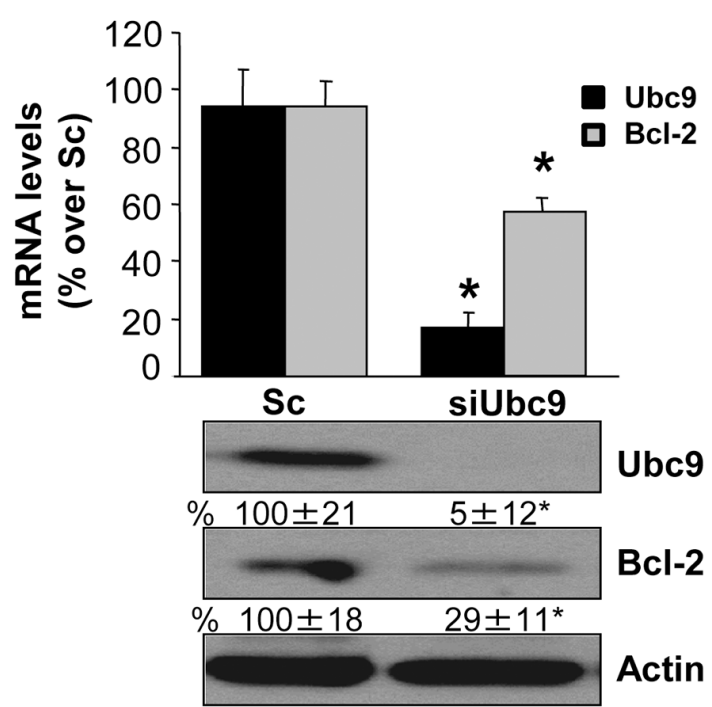

E.

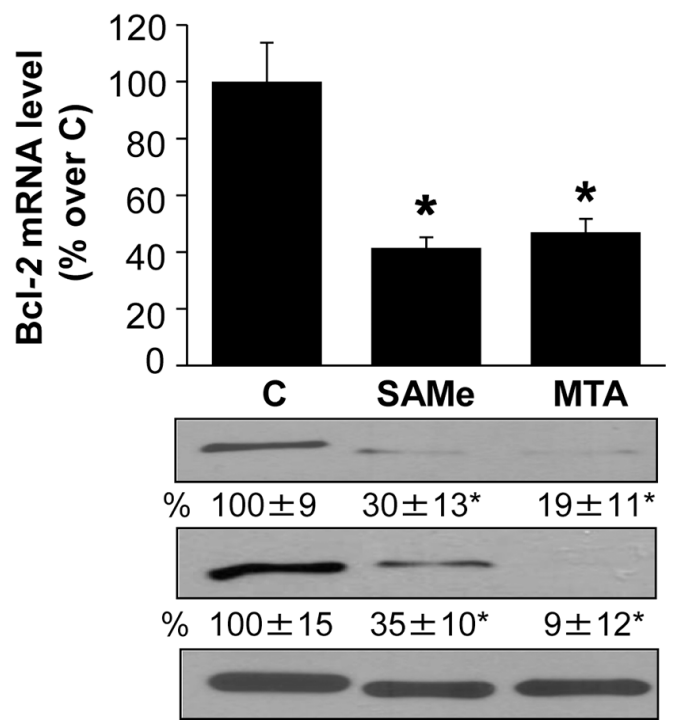

B. RKO

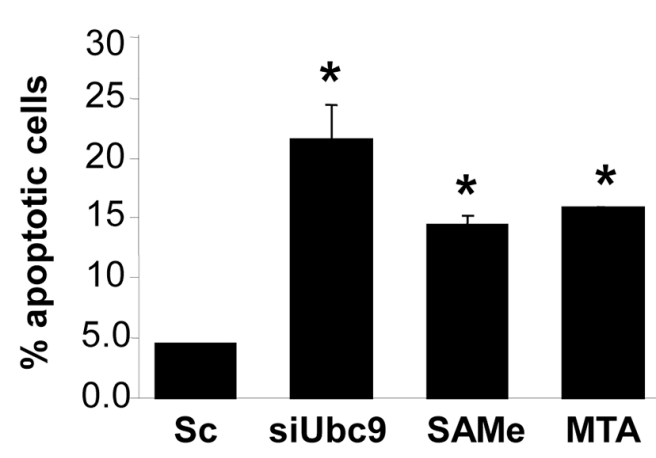

D.

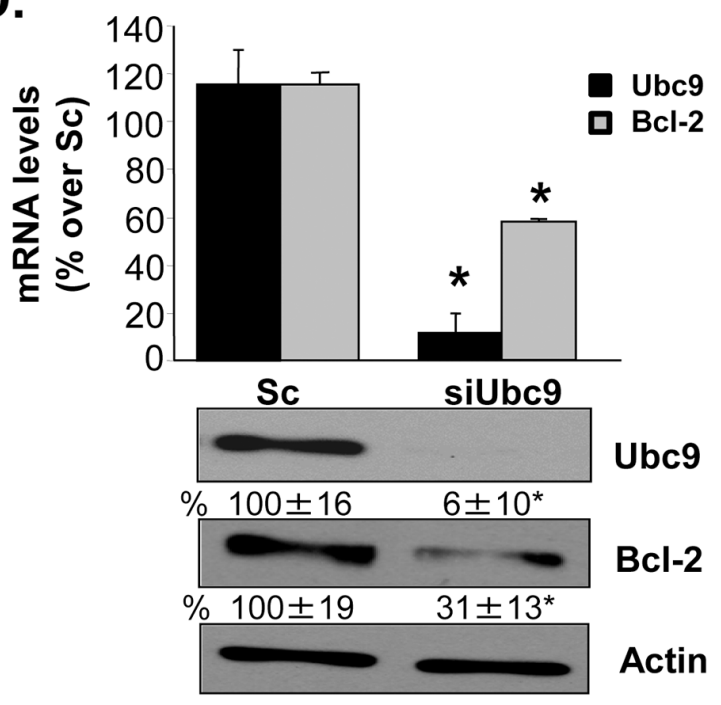

F.

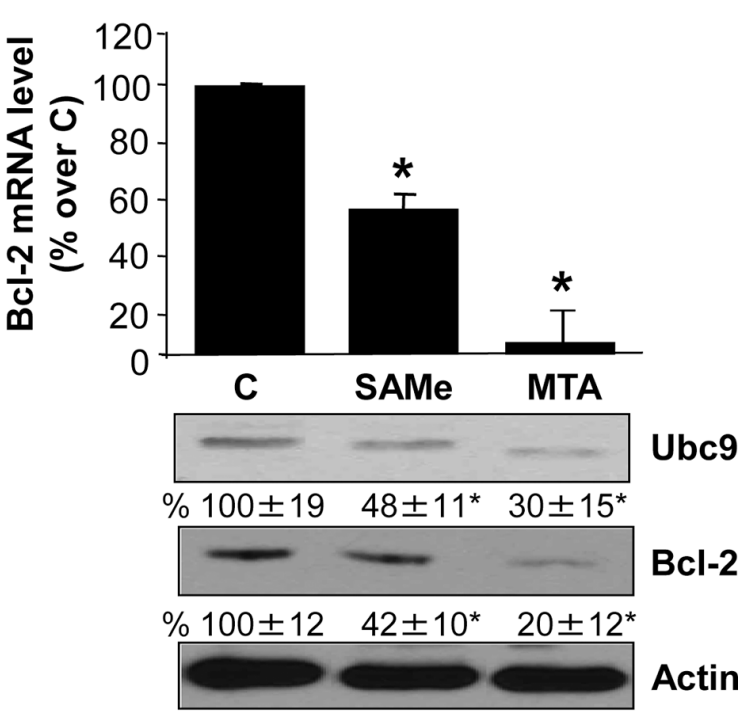

Figure 1: Ubc9 knockdown, SAMe and MTA treatment induce apoptosis and lower Bcl-2 expression in HepG2 and RKO cells. HepG2 and RKO cells were treated with siUbc 9 or scrambled siRNA (Sc, $20 \mathrm{nM})$ for 48 hours or SAMe ( $2 \mathrm{mM})$ and MTA $(1 \mathrm{mM})$ for 24 hours. A. and B. Apoptosis was analyzed by nuclei Hoechst staining. Results from 3 experiments are shown as mean $\%$ of apoptotic cells \pm SEM, ${ }^{*} p<0.001$ vs Sc. C-F. Bcl-2 expression was determined by real-time PCR and Western blotting. Bcl-2 mRNA results are expressed as mean $\%$ of Sc or control \pm SEM from 3 to 4 independent experiments performed in duplicate. ${ }^{*} p<0.001$ vs. Sc for $\mathrm{C}$ and D; ${ }^{*} p<0.001$ vs. control (C) for $\mathbf{E}$ and $\mathbf{F}$. Densitometric changes in protein levels are shown below the blots. Results are expressed as mean $\%$ of Sc or control from 3 independent experiments $\pm \mathrm{SEM},{ }^{*} p<0.02$ vs. Sc for $\mathrm{C}$ and $\mathrm{D},{ }^{*} p<0.04$ vs. control for $\mathbf{E}$ and $\mathbf{F}$. 
A.

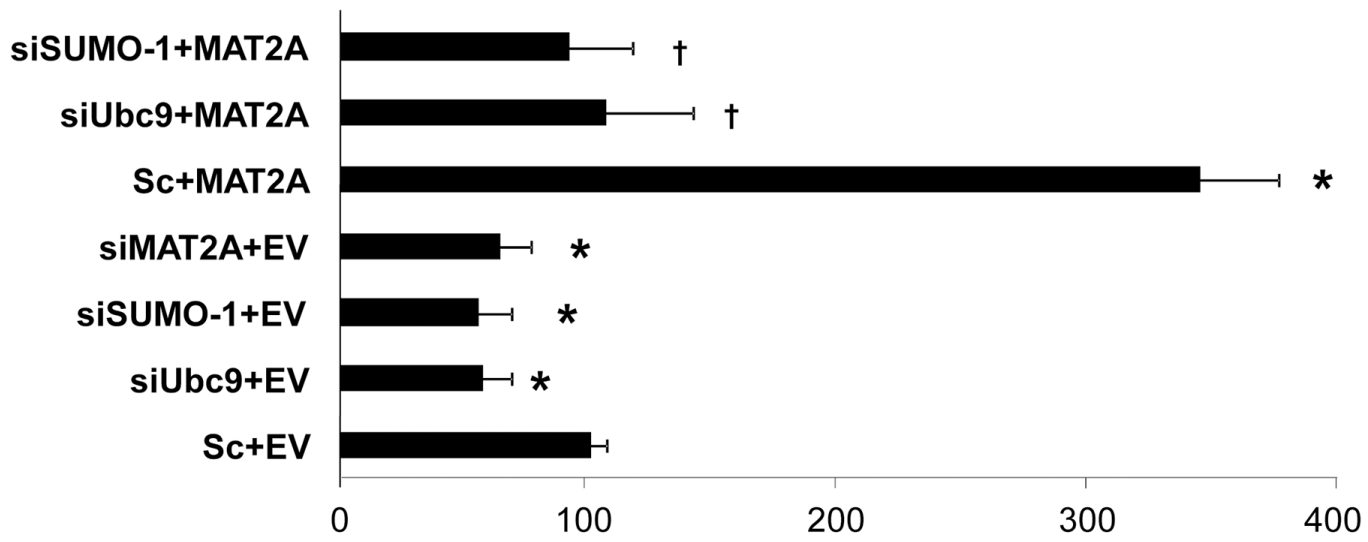

B.
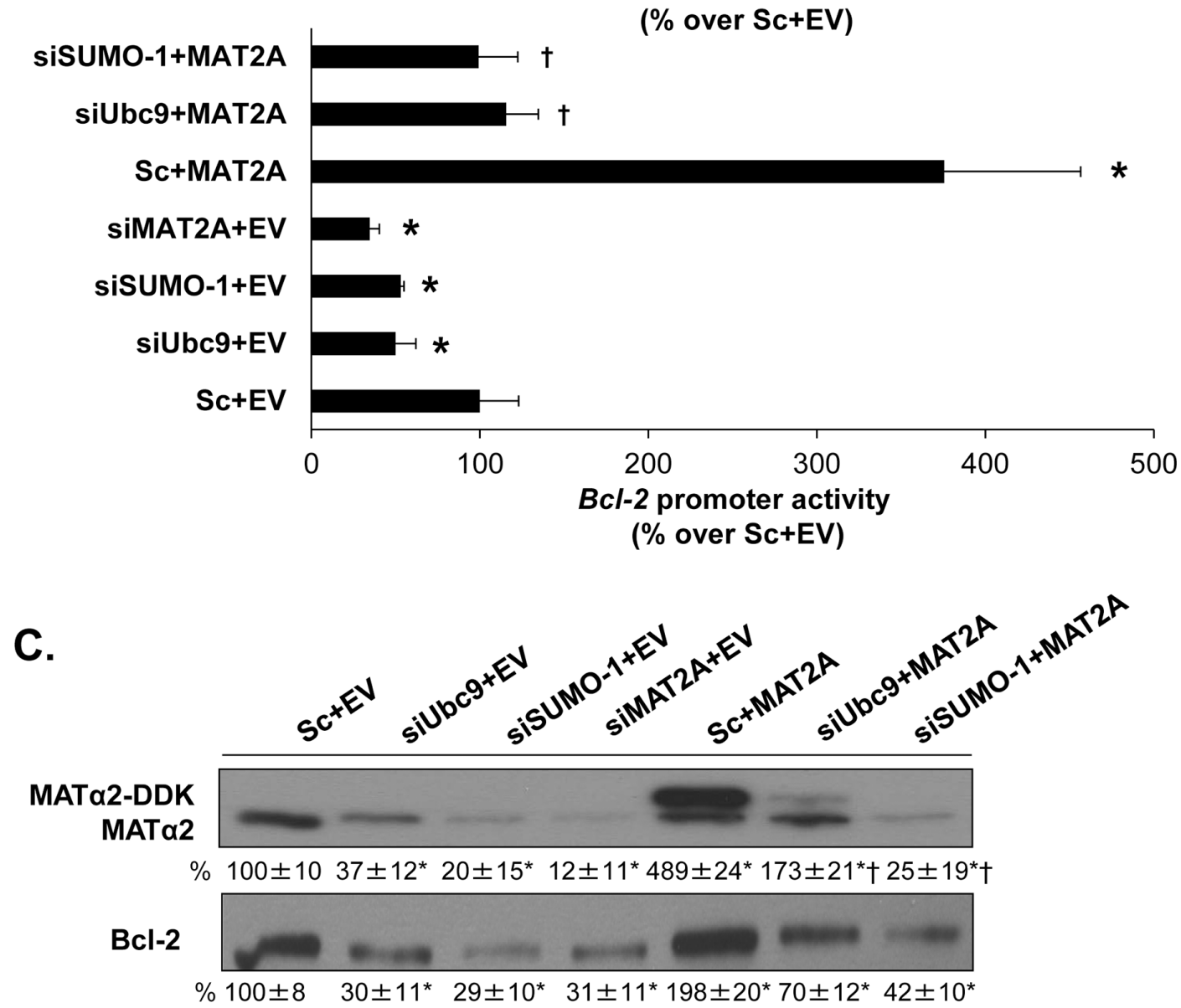

Actin

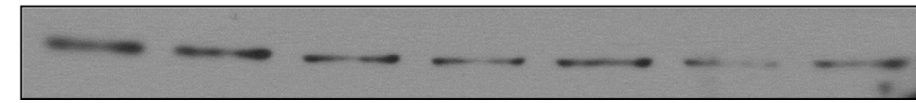

Figure 2: MAT2A and sumoylation machinery regulate Bcl-2 expression in HepG2 cells. A. HepG2 cells were transfected with siMAT2A, siUbc9 and siSUMO-1 (20 nM) or scrambled siRNA (Sc) for 48 hours and/or MAT2A overexpression vector or empty vector (EV) for 24 hours. The mRNA levels of Bcl-2 were compared to Sc+EV using real-time PCR. Results represent mean $\pm \mathrm{SEM}$ from 4 experiments in duplicates, ${ }^{*} p<0.04$ vs. Sc+EV control; $\uparrow p<0.04$ vs. Sc+MAT2A overexpression vector. B. Following the same treatments as in "A", HepG2 cells were transfected with the human $B c l-2$ promoter or pGL3-basic as described in Methods. The luciferase activity driven by $\mathrm{Bcl}-2$ promoter was normalized to that of pGL3-Basic and expressed as \% over Sc+EV. Results represent mean $\pm \mathrm{SEM}$ from 4 experiments in duplicate, ${ }^{*} p<0.04$ vs. Sc+EV control; $\uparrow p<0.03$ vs. Sc+MAT2A overexpression vector. C. Cells were treated as in 'A' and total cellular protein was subjected to Western blotting with antibodies against MAT $\alpha 2$ or Bcl-2. Densitometric changes were normalized to actin. Representative images and densitometric analysis (\% mean $\pm \mathrm{SEM}$ of Sc+EV, indicated below the blots) from 3 experiments in HepG2 cells are shown. ${ }^{*} p<0.05$ vs. $\mathrm{Sc}+\mathrm{EV}, \uparrow p<0.03$ vs. Sc+MAT2A overexpression vector. 
SUMO-1 knockdown lowered Bcl-2 protein level even more than mRNA level, whereas MAT2A overexpression raised $\mathrm{Bcl}-2$ protein level but not if cells were also treated with either siUbc9 or siSUMO-1 (Figure 2C and Supplementary Figure S1C). In addition, we found that Ubc9 and SUMO-1 silencing had no effect on MAT2A mRNA level (data not shown), but MAT $\alpha 2$ protein level fell markedly by $\sim 65 \%$ (siUbc9) to $\sim 80 \%$ (siSUMO-1) in HepG2 and RKO cells (Figure 2C and Supplementary Figure S1C). These results suggest that sumoylation machinery and MAT $\alpha 2$ protein play key roles on Bcl-2 expression at both transcriptional and post-translational levels. In addition, MAT $\alpha 2$ protein stability may also be controlled by sumoylation.

\section{DNA binding of MATa2 to $\mathrm{Bcl}-2 \mathrm{P} 2$ promoter sequences}

$\mathrm{Bcl}-2$ transcription is regulated positively by $\mathrm{Bcl}-2$ P2 promoter activity [23]. Using BindN [24] and Naïve Bayes prediction DNA-binding models, we identified several potential DNA-binding sites present in the MAT $\alpha 2$ protein sequence (Figure 3A). Also, we identified four putative MAT $\alpha 2$ protein binding sites on $\mathrm{Bcl}-2 \mathrm{P} 2$ promoter sequence from -749 to +1 using PROMO prediction software (Figure $3 \mathrm{~B}$ ). We analyzed predicted binding sites 1, 2 and 3 (Figure 3C and 3D) because the dissimilarity threshold (the parameter that controls how similar a sequence must be to the matrix) was higher than $15 \%$ rated by PROMO software. To critically analyze the ability of MAT $\alpha 2$ protein to bind $\mathrm{Bcl}-2 \mathrm{P} 2$ promoter in vitro, gel retardation and supershift analysis of these individual elements were performed. Double-stranded oligonucleotides (Supplementary Table S1) corresponding to the putative $\mathrm{Bcl}-2 \mathrm{P} 2$ promoter MAT $\alpha 2$ binding sites were examined for their ability to interact with RKO nuclear protein lysate. This analysis demonstrated that all three $\mathrm{Bcl}-2 \mathrm{P} 2$ promoter sites specifically interacted with MAT 2 2, forming complexes that supershifted in the presence of anti-MATa2 antibody (Figure 3C). Same results were obtained using nuclear protein lysate from HepG2 cells (data not shown). Direct interaction between MAT $\alpha 2$ and these DNA binding sites was further confirmed using recombinant MAT $\alpha 2$ (Figure 3D).

\section{MATa2 binds to $\mathrm{Bcl}-2 \mathrm{P} 2$ promoter in HepG2, RKO cells and human colon cancer specimens}

The results above show that MATa2 protein binds $\mathrm{Bcl}-2$ P2 promoter elements. We next used the chromatin immunoprecipitation (ChIP) assay to confirm that MAT $\alpha 2$ can bind to $B c l-2$ P2 promoter region in endogenous chromatin configuration in living cells and examine whether this is increased in human colon cancer where MAT $\alpha 2$ is overexpressed [20]. MAT $\alpha 2$ strongly interacts with the $\mathrm{Bcl}-2 \mathrm{P} 2$ promoter and Ubc9 knockdown lowered this binding in both RKO and HepG2 cells by $43 \%$ and $58 \%$, respectively (Figure $3 \mathrm{E}$ ). Figure $3 \mathrm{~F}$ shows that MAT $\alpha 2$ exhibited enhanced binding to the $\mathrm{Bcl}-2$ P2 promoter region in colorectal cancer compared with corresponding surrounding non-tumorous tissues by $88 \%$.

\section{MATa2 sumoylation in vitro}

Our results show that Ubc9 and SUMO-1 knockdown lower MAT 22 protein level in both HepG2 and RKO cells (Figure 2C and Supplementary Figure S1C). Sumoylation by SUMO-1 has been shown to control stability of its protein target [25]. Using SUMOplot, SUMOsp2.0 and GSP-SUMO-1 sumoylation prediction software, we identified four potential sumoylated sites on MAT $\alpha 2$ protein sequence (Figure 4A). To investigate whether MAT $\alpha 2$ is sumoylated in vitro, we carried out in vitro sumoylation assays using highly purified MAT $\alpha 2$ recombinant protein and commercially available SUMOylation assay kit [26]. Sumoylated target proteins show higher molecular weight compared with wild-type (WT) proteins [27]. Figure 4B shows that MAT $\alpha 2$ is sumoylated by SUMO-1, SUMO-2 and SUMO-3.

\section{MAT 22 is sumoylated in human colorectal tissues, HepG2 and RKO cells}

Since MAT 22 is localized in both nuclear and cytoplasmic compartments [28], we investigated whether MAT $\alpha 2$ is sumoylated in vivo and where the sumoylated form is localized in HepG2 cells. Figure 5A shows that MAT $\alpha 2$ is sumoylated in both compartments by SUMO-1; however, despite the fact that the bulk of total MAT $\alpha 2$ is in the cytoplasmic compartment, there is much more sumoylated MAT $\alpha 2$ in the nucleus. Knocking down Ubc9 reduced both SUMO-1-sumoylated and total MAT 2 (Figure 5B). Reverse IP using anti-SUMO-1 antibody followed by Western blotting confirmed MAT $\alpha 2$ sumoylation by SUMO-1, which is reduced comparably by either Ubc9 or SUMO-1 knockdown in HepG2 and RKO cells (Figure 5C). Finally, Figure 5D shows in paired colon cancer and adjacent non-tumorous tissues, MAT $\alpha 2$ is SUMO-1 sumoylated and SUMO-1-MAT $\alpha 2$ level is nearly doubled in colon cancer. In the same specimens the protein levels of Ubc9, MAT $\alpha 2$ and Bcl-2 are all higher in cancer.

\section{Bcl-2 directly interacts with MAT $\alpha 2$ and Ubc9 in HepG2 and RKO cells}

Since MAT $\alpha 2$ and Ubc9 knockdown lowered Bcl-2 protein level further than the mRNA level, we examined whether Bcl-2 interacts with MAT $\alpha 2$ and Ubc9 in HepG2 and RKO cells. Figure $6 \mathrm{~A}$ and $6 \mathrm{~B}$ show that Bcl-2 co-immunoprecipitated with MAT $\alpha 2$ and Ubc 9 and silencing of Ubc9 lowered their interaction. Also, we tested whether 
A.

MATa2 sumoylation prediction

\begin{tabular}{|c|c|c|c|c|c|}
\hline $\mathbf{N}$. & POSITION & PEPTIDE & SCORE & CUTOFF & SOFTWARE \\
\hline 1 & 311 & VAKSLVKGGLCRRV & 0.76 & & SUMOplot \\
\hline 2 & 340 & TSQKSER & $\begin{array}{l}3.82 \\
0.50\end{array}$ & 2.64 & $\begin{array}{l}\text { SUMOsp2.0 } \\
\text { SUMOplot }\end{array}$ \\
\hline 3 & 372 & VRDLD LKKPIYQRT & 0.80 & & SUMOplot \\
\hline 4 & 394 & WEVPKKLKY $Y^{\star \star \star \star \star \star *}$ & $\begin{array}{c}38.61 \\
2.88\end{array}$ & $\begin{array}{c}36.625 \\
2.64\end{array}$ & $\begin{array}{c}\text { GSP-SUMO-1 } \\
\text { SUMOsp2.0 }\end{array}$ \\
\hline \multicolumn{6}{|c|}{$\begin{array}{l}\text { >gi|5174529|ref|NP_005902.1| S-adenosyImethionine synthase isoform type-2 [Homo } \\
\text { sapiens] } \\
\text { MNGQLNGFHEAFIEEGTFLFTSESVGEGHPDKICDQISDAVLDAHLQQDPDAKVACETVAK } \\
\text { TGMILLAEITSRAAVYQKVVEAVKHIGYDDSKGFDYKTCNVLVALEQQSPDIAQGVHLD } \\
\text { RNEEDIGAGDQGLMFGYTDETEECMPLTIVLAHKLNAKLAELRRNGTLPWLRPSKTQV } \\
\text { TVQYMQDRGAVLPIRVHTIVISVQHDEEVCLDERDALKEKVIKAVVPAKYLDEDTIYHLQP } \\
\text { SGRFVIGGPQGDAGLTGRKIIVDTYGGWGAHGGGAFSGKDYTKVDRSAAYAARWVAKSL } \\
\text { VKGGLCRRVLVQVSYIGVSHPLSISIFHYGTSQKSERELLEIVKKNFDLRPGVIVRDLDLKK } \\
\text { PIYQRTAAYGHFGRDSFPWEVPKKLKY }\end{array}$} \\
\hline
\end{tabular}

B.

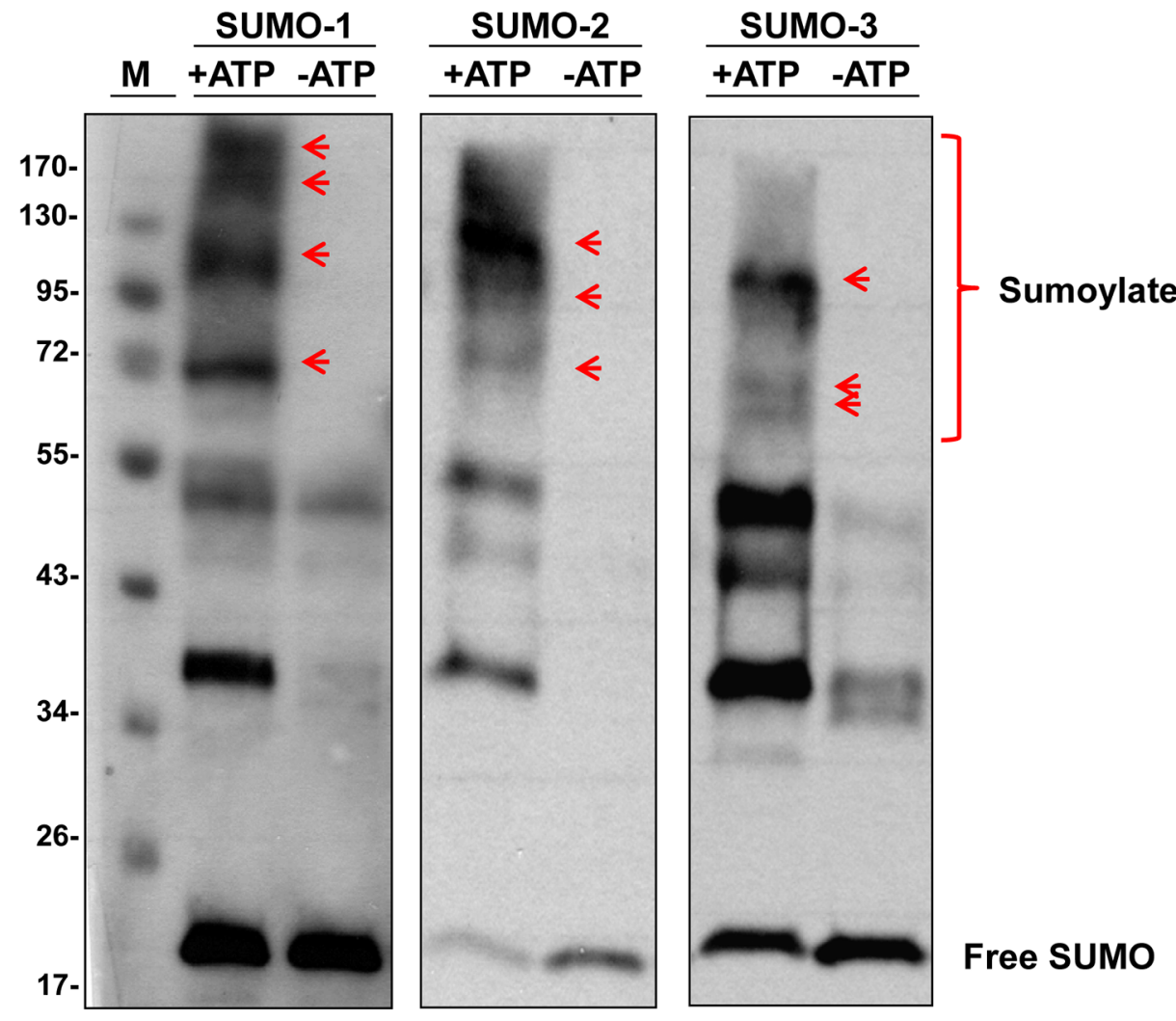

Figure 4: SUMO-binding prediction of MAT $\alpha 2$ and in vitro sumoylation. A. Prediction of potential sumoylated sites in MAT $\alpha 2$ protein sequence using the SUMOsp2.0, SUMOplot and GSP-SUMO-1 analysis tools. B. shows sumoylation of MATa2 by SUMO-1, SUMO-2 and SUMO-3 recombinant protein system as described in Methods. Sumoylation was measured using anti-SUMO-1 and antiSUMO-2/3 antibodies in Western blotting. Red arrows indicated sumoylated MAT $\alpha 2$. 
A.

B.
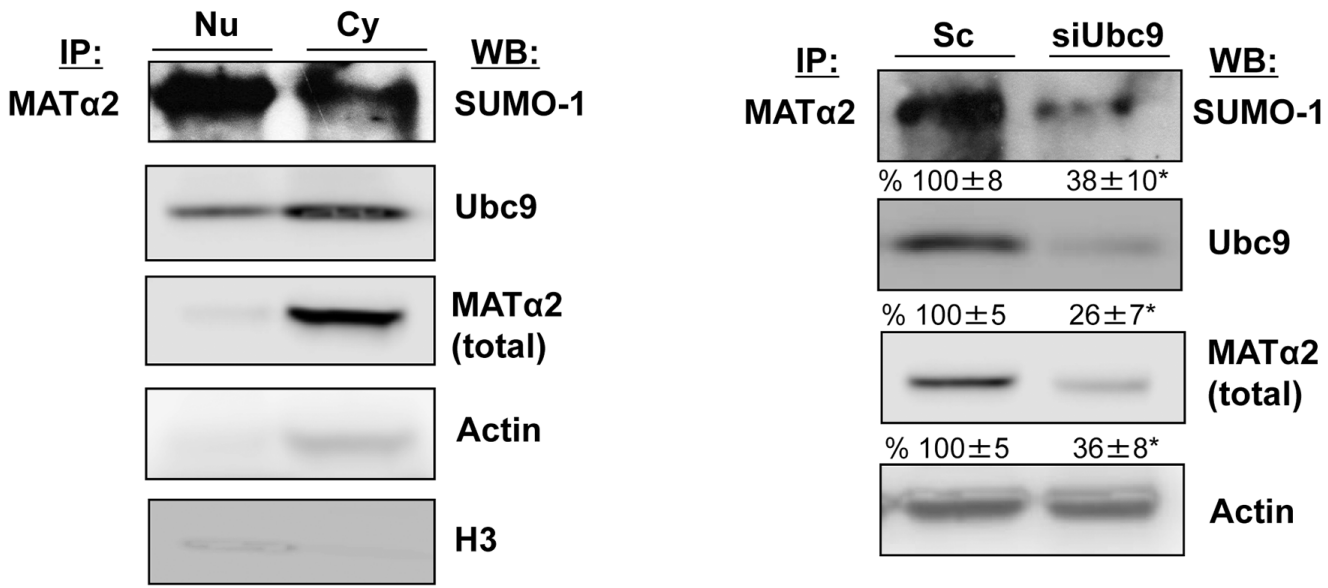

C.
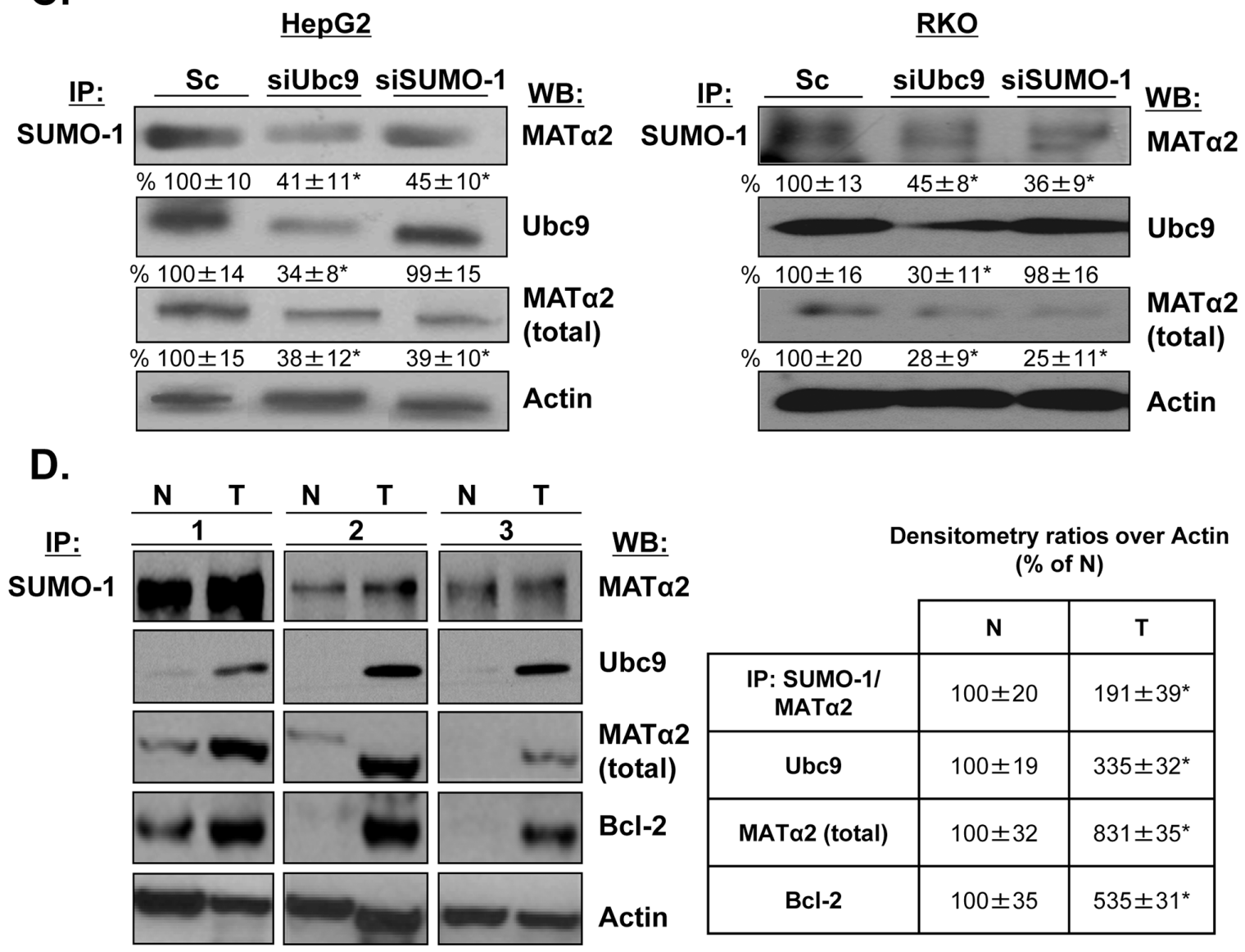

Densitometry ratios over Actin $(\%$ of $\mathrm{N})$

Figure 5: MAT 22 is sumoylated in HepG2 and RKO cells and human colon cancers. A. Nuclear and cytoplasmic proteins from HepG2 cells were immunoprecipitated with anti-MATa2 and Western blotting was carried out with anti-SUMO-1, MATa2 and Ubc9 antibodies. B. and C. HepG2 and RKO cells were treated with siUbc9 and siSUMO-1 or scrambled (Sc, $20 \mathrm{nM})$ for 48 hours and co-immunoprecipitation of MAT $\alpha 2$ or SUMO-1 was performed followed by Western blotting with anti-MAT 22 and anti-Ubc9 antibodies. Densitometric values are shown below the blots, and results represent mean \pm SEM from 3 experiments done in duplicates expressed as \% of Sc, ${ }^{*} p<0.04 v s$. Sc. D. Sumoylation of MATa2 in human colon cancer specimens (T) and corresponding non-tumorous (N) tissues are shown. The immunoprecipitation was done as described above for sumoylated MAT $\alpha 2$; total MAT $\alpha 2$, Ubc9 and Bcl-2 are also measured in the same specimens using Western blotting. Densitometric changes are shown in adjacent box, and results represent mean \pm SEM from 5 colorectal cancers expressed as $\%$ of corresponding non-tumorous $(\mathrm{N})$ tissues, ${ }^{*} p<0.05$ vs. non-tumorous tissue. 


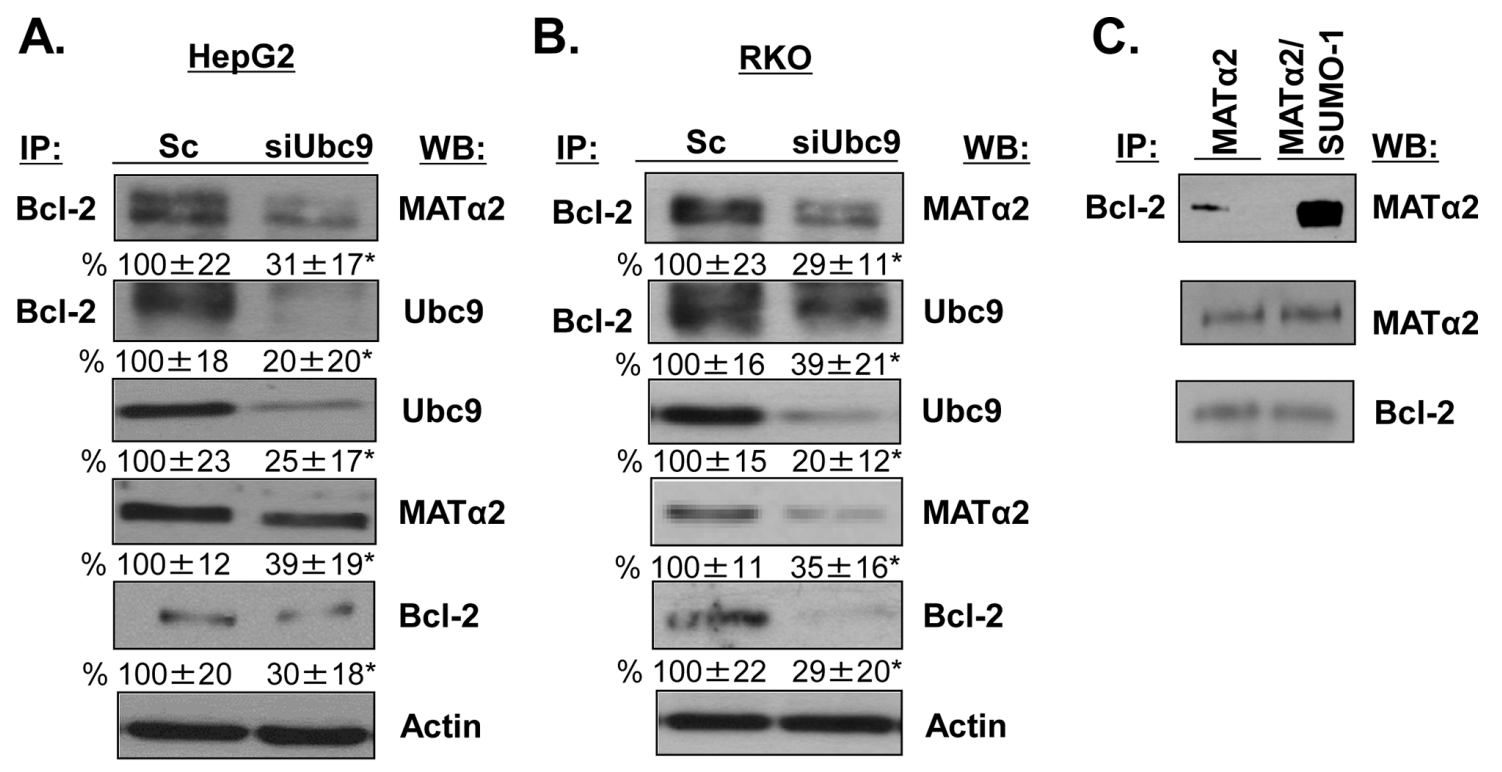

D.
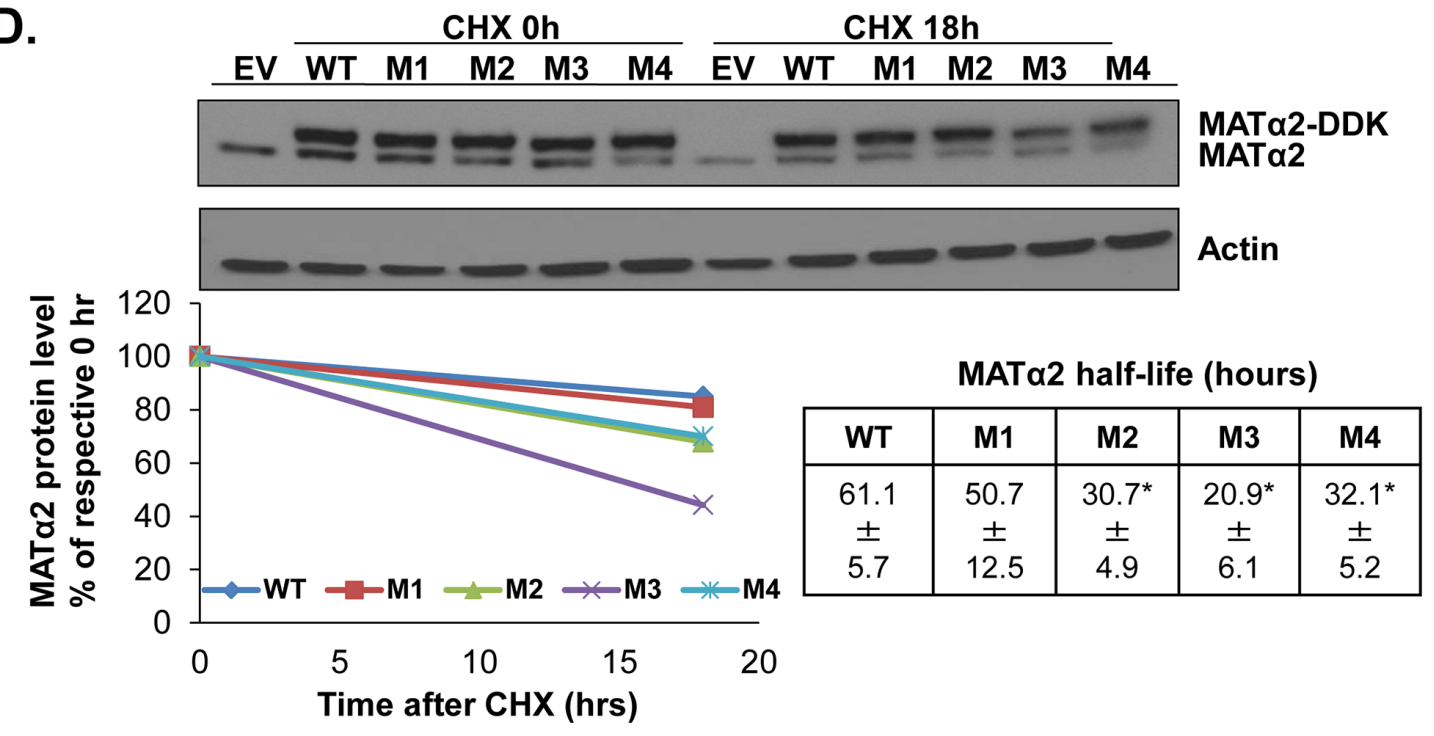

E.

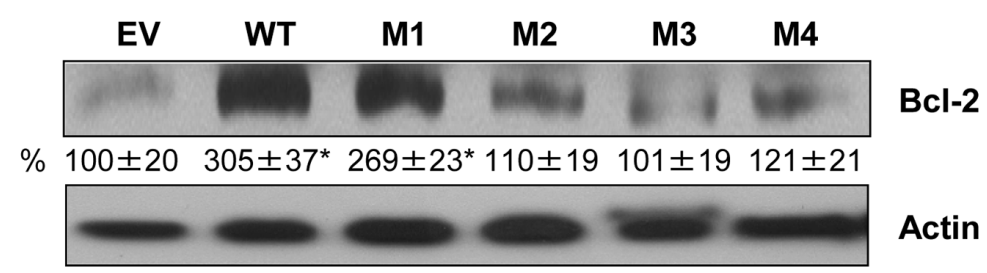

Figure 6: MAT $\alpha 2$ directly interacts with Bcl-2 and mutation at MAT 22 SUMO-binding sites affects MAT $\alpha 2$ stability and Bcl-2 protein level. A. and B. HepG2 and RKO cells were transfected with scrambled ( $\mathrm{Sc}$ ) or siUbc9 $(20 \mathrm{nM})$ for 48 hours. Co-IP analysis and Western blotting were done as described in Methods. Results are expressed as $\%$ of Sc (mean \pm SEM) from 4 independent experiments and shown below the blots, ${ }^{*} p<0.04$ vs. Sc. C. Recombinant MAT $\alpha 2$ and Bcl-2 proteins interaction in vitro was done as described in Methods. D. RKO cells were transfected with empty vector (EV), hMAT2A-WT, hMAT2A-M1, hMAT2A-M2, hMAT2A-M3 or hMAT2A-M4 for 24 hours as described in Methods. MAT 22 protein stability was determined by Western blot analyses of DDK tag following cycloheximide (CHX) treatment as described in Methods. Representative blots are shown. Protein stability was determined using linear regression and half-life calculated using equation indicated. Results represent mean \pm SEM from 3 independent experiments expressed as $\%$ of respective $0 \mathrm{hr}$ level ( $p<0.04$ between WT and MUT). E. Effects of overexpressing hMAT 2 2-WT or MAT $\alpha 2$-mutants for 36 hours on Bcl-2 protein level. Densitometric results are expressed as \% EV control (mean $\pm \mathrm{SEM}$ ) from 3 independent experiments and shown below the blot. ${ }^{*} p<0.01$ vs. EV. 
MAT 22 and Bcl-2 physically interact in vitro using highly purified Bcl-2 and MAT $\alpha 2$ recombinant proteins. Figure $6 \mathrm{C}$ shows that MAT $\alpha 2$ and Bcl-2 form a complex in vitro and sumoylated MAT $\alpha 2$ leads to higher complex formation.

\section{Mutation of MATa2 sumoylation binding sites influence protein stability of MAT $\alpha 2$ and Bcl-2}

Since knockdown of either Ubc9 or SUMO-1 lowered MAT $\alpha 2$ protein level without affecting the mRNA level, we hypothesize that sumoylation regulates MAT $\alpha 2$ protein stability. We examined whether the predicted SUMO binding sites (Figure 4A) are relevant for MAT $\alpha 2$ protein stability by mutating K311, K340, K372 and K394 and measured MAT $\alpha 2$ protein stability in RKO cells. For this purpose, we created mutations in the overexpression vector of hMAT2A DDK-tagged at K311, K340, K372 and K394 (to R311, R340, R372 and R394) (Supplementary Table S2) and examined the total MATa2 protein level using Western blotting analysis. Figure 6D shows that mutation at K340 (M2), K372 (M3) and K394 (M4) (but not K311, or M1) resulted in a less stable MATa2 as demonstrated by measurement of protein half-life in RKO cells. Overexpressing mutant MAT $\alpha 2$ constructs had no influence on the endogenous MAT $\alpha 2$ protein stability (results not shown). To test whether MAT $\alpha 2$ is required for Bcl-2 protein stability, we tested the effect of expressing MAT 22 WT or mutants for 36 hours on Bcl-2 protein level by Western blotting analysis in RKO cells. Figure $6 \mathrm{E}$ shows that MAT $\alpha 2$ WT and M1 overexpression increased Bcl-2 protein level by about 2-fold compared to empty vector control, whereas mutants M2, M3 and M4 overexpression had no effect on Bcl-2 protein level. Overexpression of WT and mutant MAT2A constructs was able to raise MAT2A mRNA level more than 300 fold over empty vector at 24 hours (Supplementary Figure S2A). Overexpressing WT, M1 and M4 also raised Bcl-2 mRNA level comparably, whereas overexpressing M2 and M3 did not significantly affect Bcl-2 mRNA level (Supplementary Figure S2B).

\section{Overexpressing stable forms of MAT $\alpha 2$ protects cancer cells from 5-fluorouracil (5-FU)-induced apoptosis}

Overexpressing WT and M1 sumoylation MATa2 mutant (stability not affected) protected against 5-FUinduced apoptosis in both HepG2 and RKO cells but M2M4 sumoylation MAT $\alpha 2$ mutants were either ineffective or minimally effective (Figure 7).

\section{Effects of MATa2 on Bcl-2 expression are independent of SAMe}

Since MAT 22 catalyzes the formation of SAMe, which could affect gene and protein expression indirectly, we compared overexpression of wild type MAT 22 or MAT $\alpha 2$ catalytic mutant (MAT 22 D134A) which lacks catalytic function [28]. Overexpression of either wild type or catalytic mutant of MAT 22 raised $\mathrm{Bcl}-2$ promoter activity (Figure 8A), mRNA (Figure 8B) and protein levels (Figure 8D), albeit the wild type construct was more inductive. This may be related to lower expression of the mutant MAT $\alpha 2$ (Figures $8 \mathrm{C}$ and 8D).

\section{DISCUSSION}

Sumoylation modifies the activity of key regulatory proteins, including oncoproteins, tumor suppressors, cell cycle regulators, and enzymes involved in DNA repair [29]. Therefore, alterations in protein sumoylation and de-sumoylation caused by deregulation of Ubc9 alone or any component of the sumoylation machinery would affect the cellular pathways linked to tumorigenesis and related biological consequences [30,31]. Sumoylation modulates many proteins implicated in apoptosis such as Fas, TNFR1, Daxx, p53 and its regulator MDM2 [32, 33] and Ubc9 has been demonstrated to regulate $\mathrm{Bcl}-2$ expression through the estrogen receptor signaling pathway in MCF-7 cells [13].

Our earlier works led us to suspect there may be interplay between sumoylation, MAT2A and Bcl-2. Specifically, Ubc9 and MAT2A expression are increased in both liver and colon cancers and SAMe, which lower both Ubc9 and MAT2A expression, induces apoptosis in these cancer cells [16]. Bcl-2 is an oncoprotein that function by promoting cancer cell survival rather than proliferation [34]. Increased Bcl-2 expression is linked to chemoresistance [35] and targeting this has been an emerging strategy in cancer treatment [36]. To examine interaction between sumoylation, MAT2A and Bcl-2, we used HepG2 and RKO cells as SAMe treatment lowered MAT2A and Ubc9 expression and induced apoptosis in these cells $[10,17,20]$. Moreover, both cell types do not express estrogen receptor $[37,38]$. We found that similar to MCF-7 cells [13], knockdown of Ubc9 in HepG2 and RKO cells also lowered Bcl-2 expression. However, the mechanism is independent of the estrogen receptor. Of considerable interest, Ubc9 knockdown lowered Bcl-2 protein level much more than mRNA level (Figure 1C-1D and Supplementary Figure S1C-S1D), suggesting that Ubc9 affects Bcl-2 expression at both transcriptional and post-translation levels. Ubc9 knockdown induced apoptosis, similar to SAMe and MTA treatment in HepG2 and RKO cells (Figure 1A-1B). SAMe and MTA treatment lowered Bcl-2 expression (Figure 1E-1F), an effect that has not been previously reported and likely also contribute to their pro-apoptotic effect in these cancer cell lines.

SAMe is the principal methyl donor and precursor of polyamines synthesized by MATIA and MAT2Aencoded isoenzymes [16]. MATIA is often silenced in human liver cancer and overexpression of MATIA in liver 


\section{$\underline{\text { HepG2 }}$}

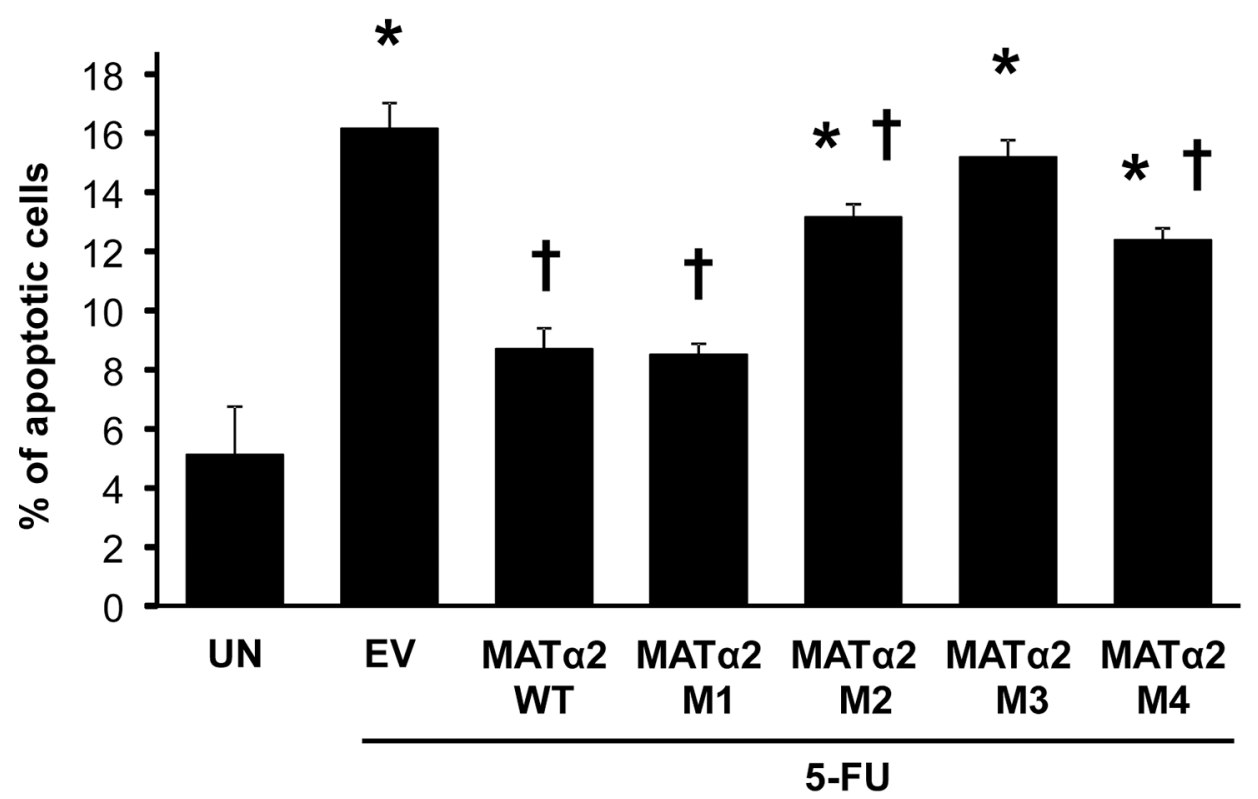

RKO

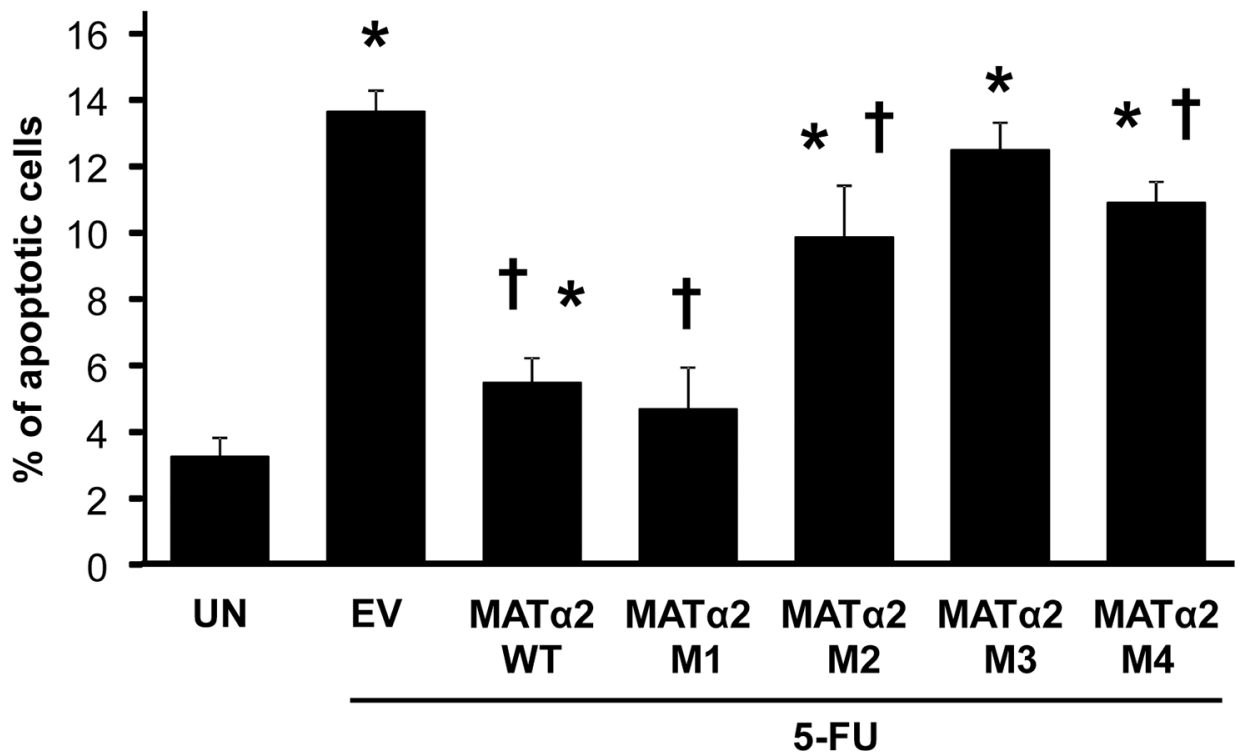

Figure 7: Overexpression of wild type but not sumoylation mutants that result in less-stable MAT 2 protect against 5-FU-induced apoptosis. HepG2 and RKO cells were transfected with empty vector (EV), hMAT2A-WT, hMAT2A-M1, hMAT2A-M2, hMAT2A-M3 or hMAT2A-M4 for 24 hours followed by treatment with 5-FU as described in Methods. Results are expressed as \% apoptotic cells from 3 independent experiments, ${ }^{*} p<0.04$ vs. untreated (UN), $\dagger p<0.04$ vs. EV. 
A.

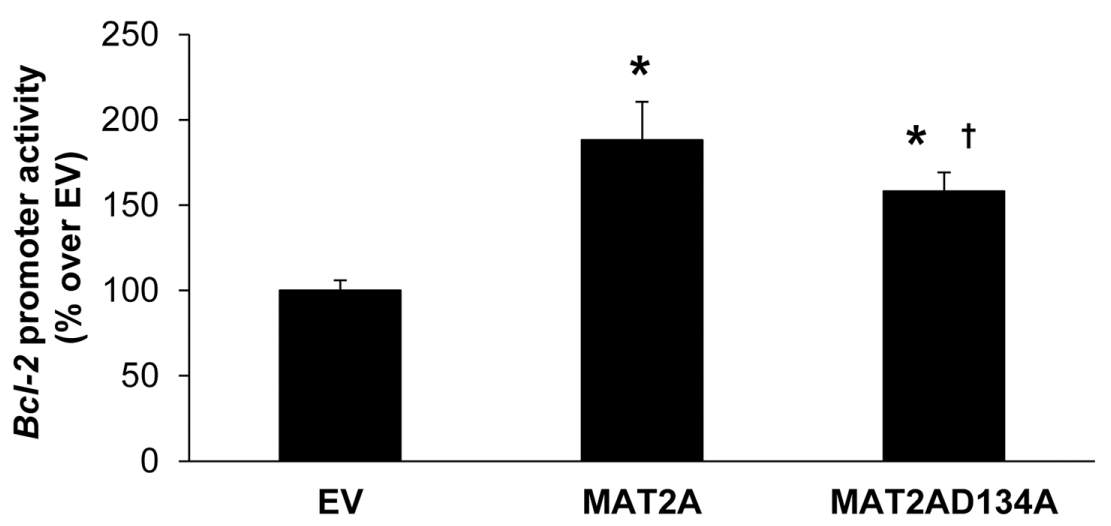

B.

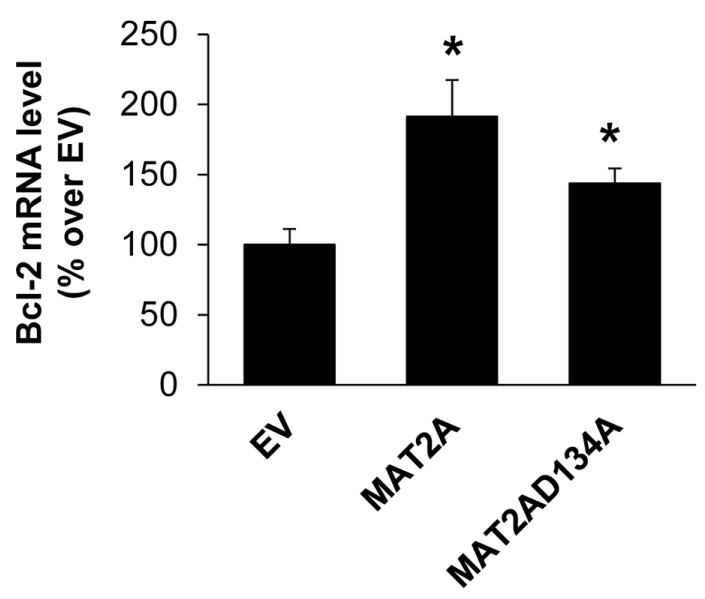

c.

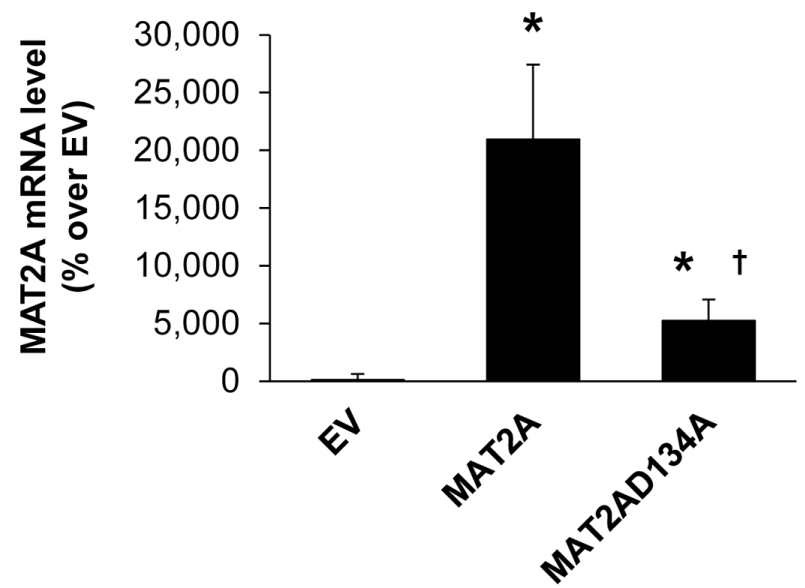

D.

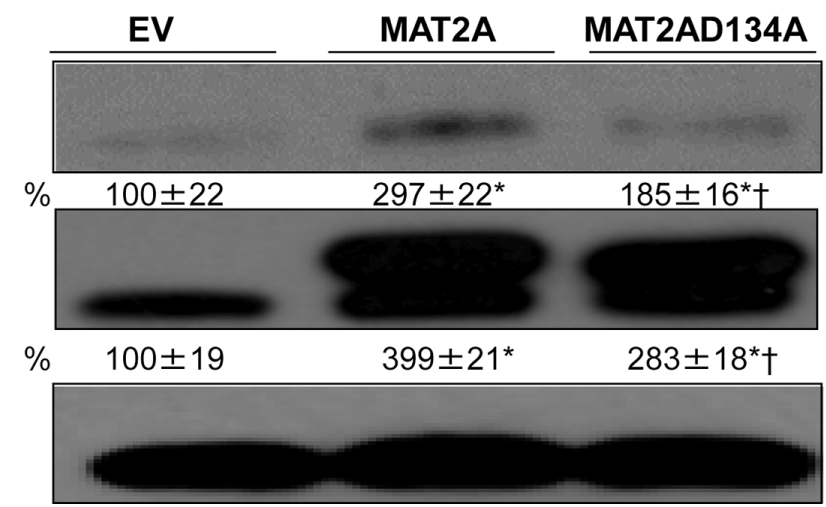

$\mathrm{Bcl}-2$

MAT $\alpha 2-D D K$ MAT $\alpha 2$

Actin

Figure 8: Effect of overexpressing MAT $\alpha 2$ catalytic mutant on Bcl-2 promoter activity and expression. RKO cells were transfected with wild type (WT) or catalytic mutant MAT2A overexpression vector or empty vector (EV) for 24 hours, with or without the human Bcl-2 promoter construct as described in Methods. A. shows effect of overexpressing the MAT2A catalytic mutant as compared to WT on $B c l-2$ promoter activity, expressed as \% over EV. Results represent mean \pm SEM from 5 experiments in duplicate, $* p<0.0001$ vs. EV control; $\uparrow p<0.05$ vs. WT MAT2A. B. and C. show effect of overexpressing WT or mutant MAT2A on Bcl-2 and MAT2A mRNA levels. Results represent mean \pm SEM from 4 experiments in duplicates, $* p<0.002$ vs. EV control; $\uparrow p<0.05$ vs. WT MAT2A. D. Cells were treated as in 'A' and total cellular protein was subjected to Western blotting with antibodies against MAT $\alpha 2$ or Bcl-2. Densitometric changes were normalized to actin. Representative images and densitometric analysis (\% mean $\pm \mathrm{SEM}$ of EV, indicated below the blots) from 6 experiments are shown. $* p<0.05$ vs. EV, $\uparrow p<0.05$ vs. WT MAT2A overexpression vector. 
cancer cells resulted in higher SAMe level and increased apoptosis [39]. Our current results are consistent with the notion that higher SAMe level led to reduced Bcl2 expression observed in MAT1A transfected HepG2 cells [40]. MAT2A expression is increased in human colon cancer tissues and cells treated with mitogens, whereas silencing MAT2A resulted in apoptosis [19, 20]. In both HepG2 and RKO cells, knockdown of MAT2A decreased, whereas MAT2A overexpression increased Bcl-2 expression (Figure 2 and Supplementary Figure S1). This appears to contradict the effect of exogenous SAMe treatment since MAT2A knockdown reduced intracellular SAMe level [17]. Thus, the effect of MAT2A expression on Bcl-2 appears to be independent of SAMe and is very similar to the effect of Ubc9 so that both MAT2A and Ubc9 knockdown lowered Bcl-2 expression at the promoter level as well at the protein level. Furthermore, overexpression of MAT2A increased $\mathrm{Bcl}-2$ promoter activity and protein level but this effect required Ubc9 (Figure 2 and Supplementary Figure S1). Since Ubd9 can have sumoylation-dependent and independent actions [41], we also examined the effect of SUMO-1 knockdown on Bcl-2 expression, which produced essentially the same effect as Ubc9 and MAT2A knockdown. Importantly, both SUMO-1 and Ubc9 knockdown drastically reduced MAT $\alpha 2$ protein level, without affecting MAT2A mRNA level. Taken together, these results support our conclusion that MAT $\alpha 2$ is sumoylated by SUMO-1, which stabilizes MAT $\alpha 2$ protein and MAT $\alpha 2$ is the link between Ubc9 and Bcl-2 expression in these cells.

MAT $\alpha 2$ regulates $\mathrm{Bcl}-2$ expression at both the promoter and protein levels. This is supported by the fact that the effect is more pronounced at the protein level when MAT2A is knocked down (Figure 2 and Supplementary Figure S1). In the only report thus far on MAT $\alpha 2$ 's ability to regulate at the transcriptional level, MAT $\alpha 2$ was found to be a transcriptional corepressor by providing a local source of SAMe and interacting with chromatin-related factors [28]. However, our results suggest MAT $\alpha 2$ can act as a bona fide transcription factor as overexpression of the catalytic mutant was equally effective in raising Bcl-2 promoter activity (Figure 8). The ability of MAT $\alpha 2$ to bind DNA is unknown and it has not been shown to activate genes transcriptionally. Consistent with previous report on transcriptional factors DNA binding [42], we found that MAT $\alpha 2$ protein could potentially bind to DNA by its C-terminal domain (Figure 3A). Following the prediction data in Figure 3B, we next examined the binding ability of MAT 22 to three potential $\mathrm{Bcl}-2 \mathrm{P} 2$ promoter binding sites (Figure 3B and Supplementary Table S1). We focused on the P2 promoter because the $\mathrm{P} 2$ promoter positively regulates $\mathrm{Bcl}-2$ expression [23]. We confirmed that MAT $\alpha 2$ can bind to all three predicted binding sites on electrophoretic mobility shift assay (EMSA) and supershift assays and the interaction is direct and requires no other proteins (Figure 3C-3D). Furthermore, these findings were verified by ChIP assays, which clearly demonstrated that MAT $\alpha 2$ interacts with $\mathrm{Bcl}-2 \mathrm{P} 2$ promoter in cells and in human colon cancer samples (Figure 3F). MAT $\alpha 2$ binding to the $\mathrm{Bcl}-2 \mathrm{P} 2$ promoter was reduced by Ubc9 knockdown, which is likely due to the fact that MAT $\alpha 2$ protein level was reduced. However, we cannot rule out the possibility that sumoylation also influences proteinprotein interaction and/or MAT $\alpha 2$ 's ability to bind DNA as sumoylation can affect DNA-binding activity of transcription factors [43].

Given the fact that both SUMO-1 and Ubc9 knockdown drastically reduced MAT $\alpha 2$ protein level without affecting its mRNA level, we suspect critical sumoylation sites are present in the MAT $\alpha 2$ protein sequence that affect its stability. Consistently, four potential sites are present in its protein sequence and we demonstrate MAT $\alpha 2$ can be sumoylated in vitro by SUMO- 1 as well as SUMO-2/3 (Figure 4B). We focused on SUMO-1 because it is known to stabilize proteins [3], while SUMO-2/3 chain formation promotes targeted protein degradation via proteasome [5]. We confirmed in vivo that MATa2 is sumoylated by SUMO-1 at baseline and Ubc9 and SUMO-1 silencing resulted in decreased MAT $\alpha 2$ protein level (Figure 5B-5C). Interestingly, SUMO-1 sumoylated MAT $\alpha 2$ is preferentially localized in the nuclear compartment (Figure 5A), and SUMO-1 sumoylation has been shown to play a key role for nuclear targeting and function of transcription factor ZIC3 [44]. We speculate a similar role may be true for SUMO-1 sumoylation of MAT $\alpha 2$, which will require further examination. MAT $\alpha 2$ is also SUMO-1 sumoylated in normal colon tissue and this is enhanced in colon cancer and higher protein levels of Ubc9, MATa 2 and Bcl-2 all occur in the cancer tissues (Figure 5D). Through point mutation analysis and cycloheximide $(\mathrm{CHX})$ pulse-chase experiments, we determined that the critical sites for MAT $\alpha 2$ stability were at the K340, K372, and K394 found in the C-terminus (Figure 6D and Supplementry Table S2). Therefore, SUMOylation of MAT $\alpha 2$ plays a critical role in its protein stability and this is likely achieved by SUMO1. The functional outcome(s) of SUMO-2/3 sumoylation of MAT $\alpha 2$ is unclear and will be a subject of future investigation.

MAT $\alpha 2$ also regulates $\mathrm{Bcl}-2$ at the protein level. To our surprise, we found that MAT $\alpha 2$ physically interacts with Bcl-2 directly and sumoylated MAT $\alpha 2$ formed complex with Bcl-2 more efficiently in vitro (Figure 6C). Consistently, we found that Ubc9 knockdown resulted in decreased Bcl-2/MAT 22 complex in HepG2 and RKO cells (Figure 6A-6B). It is noteworthy that overexpression of MATa2 sumoylation mutants M2, M3 and M4 was unable to raise Bcl-2 protein level (Figure 6E), suggesting that $\mathrm{Bcl}-2 / \mathrm{MAT} \alpha 2$ complex formation requires MAT $\alpha 2$ sumoylation and may protect Bcl-2 from degradation. This is supported by the finding that despite comparable 
elevation in Bcl-2 mRNA levels by WT, M1 and M4 MAT2A constructs, only WT and M1 raised Bcl-2 protein level. However, sumoylation at K340 (M2) and K372 (M3) may also be important for MAT 22 to bind and activate the $\mathrm{Bcl}-2$ promoter since Bcl-2 mRNA level did not increase with their overexpression. This is also consistent with the result that Ubc9 knockdown lowered MATa2 binding to the $B c l-2$ promoter (Figure 3D). Finally, we demonstrated the significance of MAT $\alpha 2$ overexpression on conferring chemoresistance as protection against 5-FUinduced apoptosis was most pronounced in cancer cells overexpressing wild type or sumoylation mutant that does not affect MAT $\alpha 2$ stability (Figure 7).

In summary, our current work uncovered, to our knowledge, a previously unreported function of MAT $\alpha 2$, namely the ability to act as a transcriptional factor that positively regulates the transcriptional activity of $\mathrm{Bcl}-2$. In addition, MAT $\alpha 2$ is sumoylated, which stabilizes the protein. Sumoylated MAT 22 is able to interact better with $\mathrm{Bcl}-2$ and this interaction stabilizes Bcl-2. These results are summarized in Figure 9. Our findings show MAT 22 regulates $\mathrm{Bcl}-2$ expression at transcriptional and posttranslational levels and is the dominant link between Ubc9 and Bcl-2. These findings provide novel insights on MAT $\alpha 2$ 's transcriptional factor function, regulation of Bcl-2, and how the interplay between Ubc9, MAT $\alpha 2$ and $\mathrm{Bcl}-2$ can confer survival benefit to the cancer cell.

\section{MATERIALS AND METHODS}

\section{Materials}

SAMe, in the stable form of disulfate p-toluene sulfonate dried powder was generously provided by Gnosis SRL (Cairate, Italy) and MTA, CHX, 5-FU, and SYBR ${ }^{\circledR}$ Green I nucleic acid gel staining were from Sigma-Aldrich (St. Louis, MO). MAT $\alpha 2$ and Bcl-2 recombinant proteins were purchased from GenWay Biotech (San Diego, CA). All other reagents were of analytical grade and obtained from commercial sources.

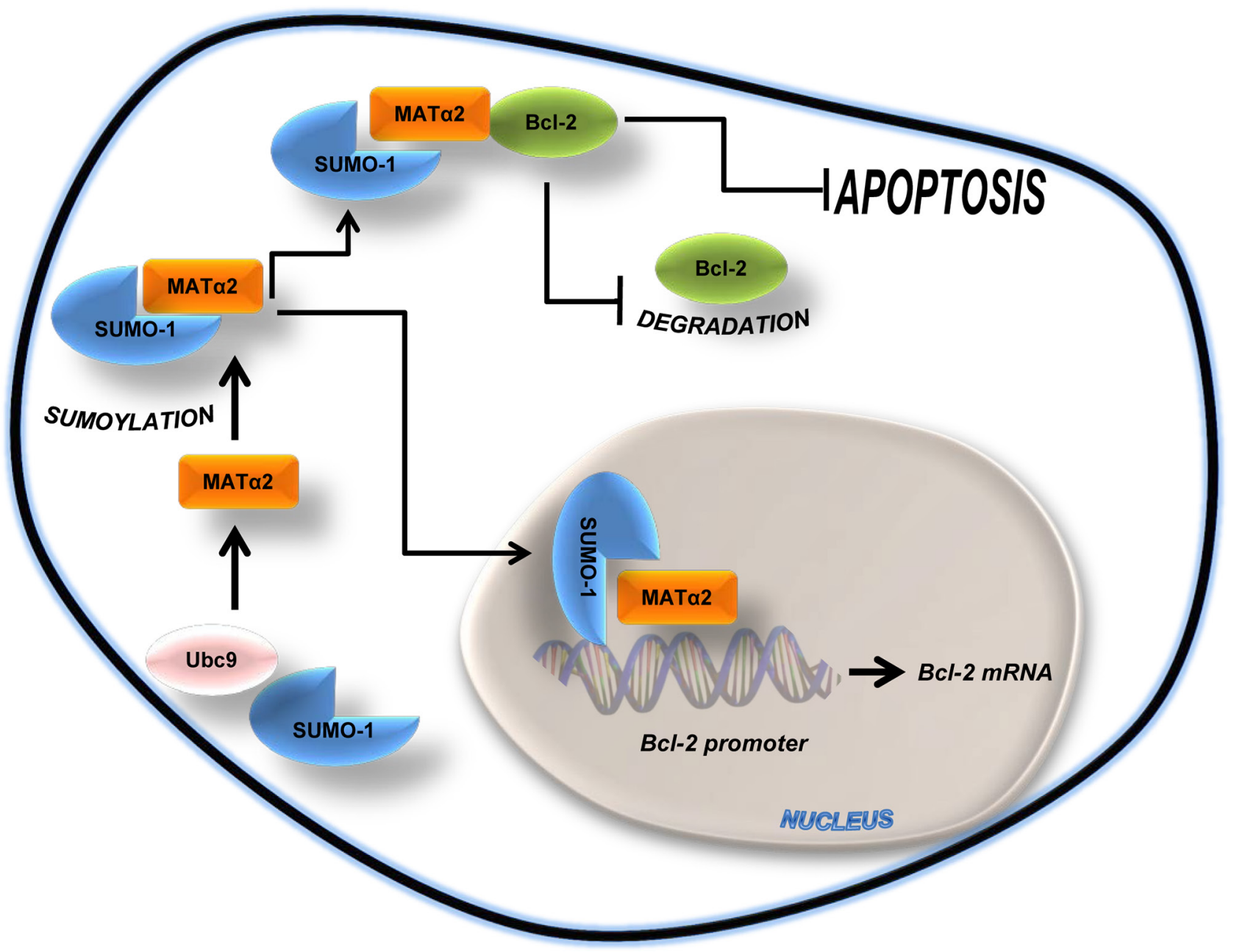

Figure 9: Simplified schematic of key findings. MAT $\alpha 2$ is sumoylated by SUMO-1 at basal level. Sumoylated MAT $\alpha 2$ regulates Bcl-2 mRNA level via binding to $\mathrm{Bcl}-2 \mathrm{P} 2$ promoter elements and increasing its activity. Sumoylated MAT $\alpha 2$ also forms a protein complex with Bcl-2, resulting in higher Bcl-2 protein stability. This positive feed forward loop protects against apoptosis. 


\section{Cell culture and SAMe/MTA treatment}

HepG2 and RKO cells were obtained from the Cell Separation and Culture Core of the University of Southern California Liver Disease Research Center and grown according to instructions provided by American Type Cell Collection. Cells were grown in $10 \%$ fetal bovine serum for 24 hours and media was changed prior to SAMe $(2 \mathrm{mmol} / \mathrm{L})$ or MTA $(1 \mathrm{mmol} / \mathrm{L})$ treatment for another 24 hours. Because of the instability of SAMe, medium was changed every 6 hours for all conditions in experiments that included SAMe.

\section{Tissue specimens}

Five pairs of colon cancer and corresponding surrounding non-tumorous tissue from surgical resection for primary colon cancer were used. Colon tissues were obtained by Professor Giordano P (Whipps Cross University Hospital, London, UK). These tissues were immediately frozen in liquid nitrogen for subsequent protein extraction. Written informed consent was obtained from each patient. The study protocol conformed to the ethical guidelines of the 1975 Declaration of Helsinki as reflected in a priori approval by Keck School of Medicine University of Southern California's human research review committee.

\section{RNA extraction and real-time polymerase chain reaction analysis}

Total RNA isolated from HepG2 and RKO cells and colon tissues as described [45] was subjected to reverse transcription (RT) by using M-MLV Reverse Transcriptase (Invitrogen, Carlsbad, CA). One $\mu$ l of RT product was subjected to quantitative real-time PCR analysis. The primers and TaqMan probes for Ubc9, Bcl-2 and MAT2A and Universal PCR Master Mix were purchased from ABI (Foster City, CA). 18SrRNA was used as housekeeping gene as described [20]. The delta $\mathrm{Ct}(\Delta \mathrm{Ct})$ obtained was used to find the relative expression of genes according to the formula: relative expression $n=2^{-\Delta \Delta \mathrm{Ct}}$, where $\Delta \Delta \mathrm{Ct}=$ $\Delta \mathrm{Ct}$ of respective genes in experimental groups $-\Delta \mathrm{Ct}$ of the same genes in control group.

\section{RNA interference}

The predesigned siRNA targeting human MAT2A (sense sequence: ACACAUUGGAUAUGAUGAUTT) was purchased from Invitrogen (Carlsbad, CA), while Ubc9 (sense sequence: GGAACUUCUAAAUGAAC CATT), SUMO-1 (sense sequence: AAGUGAAUAU AUUAAACUCA), and scrambled control siRNA were purchased from Ambion (Austin, TX). RKO and HepG2 cells were cultured in 6 -well plate $\left(0.4 \times 10^{6}\right.$ cells/well $)$ and transfected using RNAiMax (5 $\mu \mathrm{L} /$ well) from Invitrogen
(Carlsbad, CA) with MAT2A, Ubc9 and SUMO-1 siRNA (20 nM), or scrambled control siRNA for 48 hours for mRNA or protein expression, following the manufacturer's instructions.

\section{Western blots and co-immunoprecipitation (co-IP)}

Total protein extracts from HepG2, RKO and colon samples were prepared as described [17] while nuclear and cytoplasmic proteins from HepG2 were prepared using EpiQuick Nuclear Extraction Kit I (Epigenetek, Farmingdale, NY). Protein extracts were immunoprecipitated by specific MAT $\alpha 2$, SUMO-1 or Bcl-2 antibodies and processes as reported [46]. Immunoprecipitated proteins were subjected to Western blotting following standard protocols (Amersham BioSciences, Piscataway, NJ), and the membranes were probed with the anti-MAT $\alpha 2$ (Novus, Littleton, $\mathrm{CO}$ ), anti-SUMO-1, anti-Ubc9 (Genetex, Irvine, CA) and anti-Bcl-2 (Santa Cruz Biotechnology, Santa Cruz, CA) antibodies. Blots were developed using enhanced chemoluminescence.

\section{Overexpression of wt and mutant MAT2A}

Myc-DDK-tagged MAT2A overexpression vector (MAT2A-pCMV6) and negative control empty vector (pCMV6) were purchased from Origene (Rockville, MD). Catalytic MAT $\alpha 2$ mutant (D134A) lacking catalytic function was prepared as previously described [28] and verified by sequencing. Mutations of MAT $\alpha 2$ SUMO-binding Lysine sites (K311, K340, K372, K394) to Arginine were performed by Quick Change II SiteDirected Mutagenesis Kit (Stratagene, La Jolla, CA) with pCMV6 as the template. All of the primers were synthesized by Valuegene (San Diego, CA) and simply PAGE purified (Supplementary Table S2). RKO and HepG2 cells were cultured in 6-well plates $\left(0.4 \times 10^{6}\right.$ cells/ well), transfected using $5 \mu$ of JetPRIME from Polyplus (New York, NY) and $2 \mu \mathrm{g}$ of target plasmid per well. After 4 hours, the transfection medium was changed to normal medium and the cells were cultured for an additional 20 hours for promoter activity assay, mRNA and protein expression as indicated.

\section{Bcl-2 promoter reporter assay}

The $B c l$-2 promoter-luciferase reporter plasmid $\mathrm{pBS}$ (Addgene, Cambridge MA), WT and catalytic mutant MAT 22 expression plasmids were transfected into HepG2 and RKO cells $\left(0.4 \times 10^{6}\right.$ cells/well, 6-well plates $)$ using the BioT reagent (Bioland Scientific, Paramount, CA). As an internal control, the pRL4.73 plasmid (Promega, Madison, WI), which carries a Renilla luciferase gene, was co-transfected into the cells. The cells were lysed to 
measure both firefly and Renilla luciferase activities by the Dual-Luciferase Activity Detection System (Promega) 24 hours post transfection. Relative luciferase activity was calculated by normalizing the ratio of firefly/Renilla luciferase activity to that of mock-transfected cells. In some experiments cells were first treated with Ubc9, MAT2A or SUMO-1 siRNA for 24 hours prior to cotransfection with $\mathrm{Bcl}-2$ promoter construct and MAT $\alpha 2$ expression plasmid.

\section{EMSA and supershift assay}

Nuclear extracts were prepared according to the EpiQuik $^{\text {TM }}$ Nuclear Extraction Kit I protocol (Epigentek, Farmingdale, NY). Extracts were subjected to EMSA and supershift ( $3 \mu \mathrm{g}$ MAT $\alpha 2$ antibody) using the LightShift ${ }^{\circledR}$ Chemiluminescent EMSA Kit protocol (Thermo Scientific, Waltham, MA) and probes as described (Supplementary Table S1). In other experiments, recombinant MAT $\alpha 2$ (200 ng) was used for EMSA instead of nuclear extracts and nucleic acids are detected with SYBR $^{\circledR}$ Green dye $(1: 10,000)$ incubating the gels for 20 min at room temperature, and rinsed twice with deionized $\mathrm{H}^{2} \mathrm{O}$. The gels were visualized using UVP ChemiDoc- $\mathrm{It}^{\mathrm{t} 32}$ Imager (UVP, Upland, CA).

\section{ChIP assay}

ChIP assays were performed using the EZ-ChIP kit (Millipore, Billerica, MA). Sonicated chromatin immunoprecipitated with $5 \mu \mathrm{g}$ of antibody against MAT $\alpha 2$ was reverse cross-linked and PCR amplified for 35 cycles with the following Forward (Fw) and Reverse (Rev) Bcl-2 P2 promoter primer sequences: Fw, 5'-GATTCCTGCGGATTGACATTTCT-3'; Rev, 5'-CCAAGAATGCAAAGCACATCCAA-3'.

\section{In vitro sumoylation of MAT 22}

Recombinant MAT $\alpha 2(1 \mu \mathrm{g})$ was sumoylated in vitro using SUMOylation kit (Enzo Life Sciences, Farmingdale, $\mathrm{NY}$ ) in a final volume of $10 \mu \mathrm{l}$ containing $55 \mathrm{mM}$ Tris (pH 7.5), $5.5 \mathrm{mM} \mathrm{MgCl}, 2.2 \mathrm{mM}$ ATP and $5.5 \mathrm{mM}$ dithiothreitol. Sumoylation reactions were incubated at $37^{\circ} \mathrm{C}$ for 4 hours, after which proteins were analyzed by Western blotting with SUMO-1 and SUMO-2/3 antibodies.

\section{MATa2 and Bcl-2 in vitro interaction assay}

Recombinant Bcl-2 (1 $\mu \mathrm{g})$ was pre-incubated with Bcl-2 agarose-conjugated antibody $(20 \mu \mathrm{g})$ (Santa Cruz Biotechnology, Santa Cruz, CA) in $500 \mu \mathrm{L}$ final volume of incubation buffer $(150 \mathrm{mM} \mathrm{NaCl}, 50 \mathrm{mM}$ Tris- $\mathrm{HCl}$, $1 \mathrm{mM}$ EDTA, $1 \mathrm{mM}$ EGTA, $25 \mathrm{mM} \mathrm{NaF}, 1 \% \mathrm{NP}-40$ ) at $4^{\circ} \mathrm{C}$ on rotating device for 1 hour. Next, we added $1 \mu \mathrm{g}$ of recombinant MAT $\alpha 2$ or sumoylated MAT $\alpha 2$ prepared as described above, at $4^{\circ} \mathrm{C}$ for 2 hours with rotation. Pellet agarose was washed five times with incubation buffer. Finally, Bcl-2/MAT $\alpha 2$, Bcl-2/sumoylated-MAT $\alpha 2$ complex interactions, $\mathrm{Bcl}-2$ and MAT $\alpha 2$ loading control samples (prior to in vitro sumoylation and complex interaction) were analyzed by Western blotting using Bcl-2 and MAT $\alpha 2$ antibodies.

\section{Protein stability assay and half-life determination}

CHX (5 $\mu \mathrm{g} / \mathrm{ml})$ was added to RKO cells 18 hours after transfection with $2 \mu \mathrm{g}$ of wild type MAT $\alpha 2-$ pCMV4 or MAT 22 sumoylation mutant plasmids per well. Protein levels were determined at indicated time points by Western blotting as described above using antiMAT $\alpha 2$ antibody. The relative amount of MAT $\alpha 2-D D K$ protein was evaluated by densitometry and normalized to actin. Endogenous and DDK-tagged MAT $\alpha 2$ bands were separately analyzed. Protein half-life was determined for each experiment using linear regression analysis as we described [10].

\section{5-FU treatment in vitro and apoptosis assay}

Seventy percent confluent RKO and HepG2 cells were treated with $12.5 \mu \mathrm{M}$ of $5-\mathrm{FU}$ in fresh growth medium for 24 hours after transfection with $2 \mu \mathrm{g}$ of wild type MAT $22-$ pCMV4 or MAT 22 sumoylation mutant plasmids per well. The percentage of apoptotic cells was examined using Hoechst 33258 staining method as we described [19].

\section{Statistical analysis}

Data are expressed as mean \pm SEM. Statistical analysis was performed using ANOVA and Fisher's test. For mRNA and protein levels, ratios of genes and proteins to respective housekeeping densitometric values were compared. Significance was defined by $p<0.05$.

\section{Abbreviations}

5-FU, 5-fluorouracil; Bcl-2, B-Cell CLL/lymphoma 2; ChIP, Chromatin Immunoprecipitation; CHX, cycloheximide; Co-IP, co-immunoprecipitation; EMSA, Electrophoretic mobility shift assay; MAT, methionine adenosyltransferase; MTA, methylthioadenosine; PCR, polymerase chain reaction; SAMe, S-adenosylmethionine; siRNA, small interfering RNA; SUMO, ubiquitin-related modifier; Ubc9, ubiquitin-conjugating enzyme 9; WB, Western Blotting; WT, wild type. 


\section{ACKNOWLEDGMENTS AND FUNDING}

This work was supported by NIH grants R01DK051719 and R01AT004896 (SC Lu and JM Mato), K01 AA022372 (ML Tomasi), and Plan Nacional of I+D SAF 2014-52097R, and Departamento de Educación del Gobierno Vasco (JM Mato). HepG2 and RKO cells were provided by the Cell Separation and Culture Core of the USC Research Center for Liver Diseases (P30DK48522). The funders had no role in study design, data collection and analysis, decision to publish, or preparation of the manuscript.

\section{CONFLICTS OF INTEREST}

Nothing to report.

\section{REFERENCES}

1. Geiss-Friedlander R, Melchior F. Concepts in sumoylation: a decade on. Nat Rev Mol Cell Biol. 2007; 8:947-956.

2. Saitoh H, Hinchey J. Functional heterogeneity of small ubiquitin-related protein modifiers SUMO-1 versus SUMO2/3. J Biol Chem. 2000; 275:6252-6258.

3. Ghioni P, D'Alessandra Y, Mansueto G, Jaffray E, Hay RT, La Mantia G, Guerrini L. The protein stability and transcriptional activity of p63alpha are regulated by SUMO-1 conjugation. Cell Cycle. 2005; 4:183-190.

4. Wang Y, Dasso M. SUMOylation and deSUMOylation at a glance. J Cell Sci. 2009; 122:4249-4252.

5. Miteva M, Keusekotten K, Hofmann K, Praefcke GJ, Dohmen RJ. Sumoylation as a signal for polyubiquitylation and proteasomal degradation. Subcell Biochem. 2010; 54:195-214.

6. Aillet F, Lopitz-Otsoa F, Egaña I, Hjerpe R, Fraser P, Hay RT, Rodriguez MS, Lang V. Heterologous SUMO-

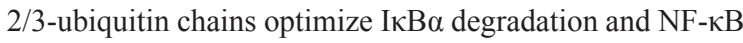
activity. PLoS One. 2012; 7:e51672.

7. Johnson ES. Protein modification by SUMO. Annu Rev Biochem. 2004; 73:355-382.

8. Zilio N, Williamson CT, Eustermann S, Shah R, West SC, Neuhaus D, Ulrich HD. DNA-dependent SUMO modification of PARP-1. DNA Repair (Amst). 2013; 12:761-773.

9. Gareau JR, Lima CD. The SUMO pathway: emerging mechanisms that shape specificity, conjugation and recognition. Nat Rev Mol Cell Biol. 2010; 11:861-871.

10. Tomasi ML, Tomasi I, Ramani K, Pascale RM, Xu J, Giordano P, Mato JM, Lu SC. S-adenosylmethionine regulates ubiquitin-conjugating enzyme 9 protein expression and sumoylation in murine liver and human cancers. Hepatology. 2012; 56:982-993.

11. Li H, Gao H, Bijukchhe SM, Wang Y, Li T. PIAS3 may represent a potential biomarker for diagnosis and therapeutic of human colorectal cancer. Med Hypotheses. 2013; 81:1151-1154.

12. Sun L, Li H, Chen J, Iwasaki Y, Kubota T, Matsuoka M, Shen A, Chen Q, Xu Y. PIASy mediates hypoxia-induced SIRT1 transcriptional repression and epithelial-tomesenchymal transition in ovarian cancer cells. J Cell Sci. 2013; 126:3939-3947.

13. Lu Z, Wu H, Mo YY. Regulation of bcl-2 expression by Ubc9. Exp Cell Res. 2006; 312:1865-1875.

14. Mo YY, Yu Y, Theodosiou E, Ee PL, Beck WT. A role for Ubc9 in tumorigenesis. Oncogene. 2005; 24:2677-2683.

15. Adams JM, Cory S. The Bcl-2 apoptotic switch in cancer development and therapy. Oncogene. 2007; 26:1324-1337.

16. Lu SC, Mato JM. S-adenosylmethionine in liver health, injury and cancer. Physiol Rev. 2012; 92:1515-1542.

17. Ramani K, Yang HP, Xia M, Iglesias Ara A, Mato JM, Lu SC. Leptin's mitogenic effect in human liver cancer cells requires induction of both methionine adenosyltransferase 2A and 2B. Hepatology. 2008; 47:521-531.

18. Yang HP, Li TWH, Peng J, Mato JM, Lu SC. Insulin-like growth factor 1 activates methionine adenosyltransferase 2A transcription by multiple pathways in human colon cancer cells. Biochem J. 2011; 436:507-516.

19. Tomasi ML, Ryoo M, Skay A, Tomasi I, Giordano P, Mato JM, Lu SC. Polyamine and methionine adenosyltransferase $2 \mathrm{~A}$ crosstalk in human colon and liver cancer. Exp Cell Res. 2013; 319:1902-1911.

20. Chen H, Xia M, Lin M, Yang H, Kuhlenkamp J, Li T, Sodir NM, Chen YH, Josef-Lenz H, Laird PW, Clarke S, Mato JM, Lu SC. Role of methionine adenosyltransferase 2A and S-adenosylmethionine in mitogen-induced growth of human colon cancer cells. Gastroenterology. 2007; 133:207-218.

21. Handayani T, Sakinah S, Nallappan M, Pihie AH. Regulation of p53-, Bcl-2- and caspase-dependent signaling pathway in xanthorrhizol-induced apoptosis of HepG2 hepatoma cells. Anticancer Res. 2007; 27:965-971.

22. Yao Y, Huang C, Li ZF, Wang AY, Liu LY, Zhao XG, Luo Y, Ni L, Zhang WG, Song TS. Exogenous phosphatidylethanolamine induces apoptosis of human hepatoma HepG2 cells via the bcl-2/Bax pathway. World J Gastroenterol. 2009; 15:1751-1758.

23. Catz SD, Johnson JL. Transcriptional regulation of bcl-2 by nuclear factor kappa B and its significance in prostate cancer. Oncogene. 2001; 20:7342-7351.

24. Wang L, Brown SJ. BindN: a web-based tool for efficient prediction of DNA and RNA binding sites in amino acid sequences. Nucleic Acids Res. 2006; 34:243-248.

25. Klenk C, Humrich J, Quitterer U, Lohse MJ. SUMO-1 controls the protein stability and the biological function of phosducin. J Biol Chem. 2006; 281:8357-8364.

26. Elmore ZC, Donaher M, Matson BC, Murphy H, Westerbeck JW, Kerscher O. Sumo-dependent substrate 
targeting of the SUMO protease Ulp1. BMC Biol. 2011; 9:74.

27. Stielow C, Stielow B, Finkernagel F, Scharfe M, Jarek M, Suske G. SUMOylation of the polycomb group protein L3MBTL2 facilitates repression of its target genes. Nucleic Acids Res. 2014; 42:3044-3058.

28. Katoh Y, Ikura T, Hoshikawa Y, Tashiro S, Ito T, Ohta M, Kera Y, Noda T, Igarashi K. Methionine adenosyltransferase II serves as a transcriptional corepressor of Maf oncoprotein. Mol Cell. 2011; 41:554-566.

29. Gill G. Post-translational modification by the small ubiquitin-related modifier SUMO has big effects on transcription factor activity. Curr Opin Genet Dev. 2003; 13:108-113.

30. Driscoll JJ, Pelluru D, Lefkimmiatis K, Fulciniti M, Prabhala RH, Greipp PR, Barlogie B, Tai YT, Anderson KC, Shaughnessy JD Jr, Annunziata CM, Munshi NC. The sumoylation pathway is dysregulated in multiple myeloma and is associated with adverse patient outcome. Blood. 2010; 115:2827-2834.

31. Alshareeda AT, Negm OH, Green AR, Nolan C, Tighe P, Albarakati N, Sultana R, Madhusudan S, Ellis IO, Rakha EA. SUMOylation proteins in breast cancer. Breast Cancer Res Treat. 2014; 144:519-530.

32. Buschmann T, Fuchs SY, Lee CG, Pan ZQ, Ronai Z. SUMO-1 Modification of Mdm2 prevents its selfubiquitination and increases $\mathrm{Mdm} 2$ ability to ubiquitinate p53. Cell. 2000; 101:753-762.

33. Santiago A, Li D, Zhao LY, Godsey A, Liao D. p53 SUMOylation promotes its nuclear export by facilitating its release from the nuclear export receptor CRM1. Mol Biol Cell. 2013; 24:2739-2752.

34. Yip KW, Reed JC. Bcl-2 family proteins and cancer. Oncogene. 2008; 27:6398-6406.

35. Prabhudesai SG, Rekhraj S, Roberts G, Darzi AW, Ziprin P. Apoptosis and chemo-resistance in colorectal cancer. J Surg Oncol. 2007; 96:77-88.

36. Azmi AS, Wang Z, Philip PA, Mohammad RM, Sarkar FH. Emerging Bcl-2 inhibitors for the treatment of cancer. Expert Opin Emerg Drugs. 2011; 16:59-70.

37. Issa JPJ, Ottaviano YL, Celano P, Hamilton SR, Davidson NE, Baylin SB. Methylation of the oestrogen receptor $\mathrm{CpG}$ island links ageing and neoplasia in human colon. Nature Genetics. 1994; 7:536-540.

38. Kelly LA, Seidlova-Wuttke D, Wuttke W, O'Leary JJ, Norris LA. Estrogen receptor alpha augments changes in hemostatic gene expression in HepG2 cells treated with estradiol and phytoestrogens. Phytomedicine. 2014; 21:155-158.

39. Li J, Ramani K, Sun Z, Zee C, Grant EG, Yang HP, Xia M, Oh P, Ko K, Mato JM, Lu SC. Forced expression of methionine adenosyltransferase $1 \mathrm{~A}$ in human hepatoma cells suppresses in vivo tumorigenesis in mice. Am J Pathol. 2010; 176:2456-2466.

40. Frau M, Tomasi ML, Simile MM, Demartis MI, Salis F, Latte G, Calvisi DF, Seddaiu MA, Daino L, Feo CF, Brozzetti S, Solinas G, Yamashita S, et al. Role of transcriptional and posttranscriptional regulation of methionine adenosyltransferases in liver cancer progression. Hepatology. 2012; 56:165-175.

41. Zhu S, Sachdeva M, Wu F, Lu Z, Mo YY. Ubc9 promotes breast cell invasion and metastasis in a sumoylation-independent manner. Oncogene. 2010; 29:1763-1772.

42. Hakimi MA, Privat I, Valay JG, Lerbs-Mache S. Evolutionary conservation of C-terminal domains of primary sigma70-type transcription factors between plants and bacteria. J Biol Chem. 2000; 275:9215-9221.

43. Ouyang J, Valin A, Gill G. Regulation of transcription factor activity by SUMO modification. Methods Mol Biol. 2009; 497:141-152.

44. Chen L, Ma Y, Qian L, Wang J. Sumoylation regulates nuclear localization and function of zinc finger transcription factor ZIC3. Biochim Biophys Acta. 2013; 1833:2725-2733.

45. Yang HP, Ara AI, Magilnick N, Xia M, Ramani K, Chen H, Lee TD, Mato JM, Lu SC. Expression pattern, regulation, and functions of methionine adenosyltransferase 2 beta splicing variants in hepatoma cells. Gastroenterology. 2008; 134:281-291.

46. Pascale RM, Simile MM, De Miglio MR, Muroni MR, Calvisi DF, Asara G, Casabona D, Frau M, Seddaiu MA, Feo F. Cell cycle deregulation in liver lesions of rats with and without genetic predisposition to hepatocarcinogenesis. Hepatology. 2002; 35:1341-1350. 